\title{
Fetal and Maternal Physiology and Ultrasound Diagnosis
}

Aida Salihagic Kadic, Maja Predojevic, Asim Kurjak

\begin{abstract}
Fetal developmental potential is determined at the moment of conception by genetic inheritance. However, this development is modulated by environmental factors. It is important to recognize that both, the mother and the fetus, actively participate in the maintenance of the physiological intrauterine environment. Unfortunately, the fetus is not entirely protected from harmful influences of the external factors. By altering the intrauterine environment, these factors can have a long-term effect on fetal health.
\end{abstract}

Keywords: Physiological intrauterine environment, Genetic inheritance, Environmental factors.

How to cite this article: Kadic AS, Predojevic M, Kurjak A. Fetal and Maternal Physiology and Ultrasound Diagnosis. Donald School J Ultrasound Obstet Gynecol 2013;7(1):9-35.

\section{Source of support $\mathrm{Nil}$}

\section{Conflict of interest: None declared}

\section{INTRODUCTION}

Human life does not begin with birth. Normal development of the human being lasts 280 days before parturition. In prenatal growth and development, the placenta plays a key role. It has numerous functions essential for maintaining the pregnancy and promoting normal fetal development. During intrauterine period, the fetus gradually begins to perform many vital physiological functions. Furthermore, through 9 months of gestation, a repertoire of fetal functions and activities constantly expands. Development of modern imaging methods has revealed the existence of a full range of fetal movement patterns, even facial movements similar to emotional expressions in adults. Indeed, the world in utero is fascinating. Therefore, the birth is not the beginning, but only a new chapter in the story of human life.

\section{PLACENTA}

'The vessels join to the uterus like the roots of plants, and through them the embryo receives its nourishment.' A ristotle, De Generatione A nimalium, B ook II.

\section{DEVELOPMENT OF THE PLACENTA}

The placenta is an organ that is indispensable for the transfer of nutrients and gases from the mother to the fetus and the removal of fetal waste products. Placenta can be defined as a fusion of fetal membranes with the uterine mucosa. The development of the placenta starts with the implantation, in the moment when the blastocyst begins the invasion of the endometrium, about the 6th day after conception. ${ }^{1}$ Prior to implantation in the uterine lining, blastocyst consists of an external, single-layer, cellular component named the trophoblast and the inner cell mass, embryoblast. A fter the trophoblast has attached to the endometrial epithelium, rapid cellular proliferation occurs and the trophoblast differentiates into two layers consisting of the inner cytotrophoblast and an outer syncytiotrophoblast, a multinucleated mass without cellular boundaries. Syncytial trophoblast processes extend through the endometrial epithelium to invade the endometrial stroma. Stromal cells surrounding the implantation site become laden with lipids and glycogen, develop into polyhedral shape, and are referred to as decidual cells. These decidual cells degenerate in the region of the invading syncytiotrophoblast and provide nutrition to the developing embryo. ${ }^{2}$ At day 7 and 8 after conception, the blastocyst has completely crossed the epithelium and is embedded within the endometrium. At day 8 and 9 postconception, the syncytiotrophoblast generates a number of fluid-filled spaces within its mass. These spaces flow together forming larger lacunae and are finally separated by parts of the syncytiotrophoblast (trabeculae) that cross the syncytial mass from the embryonic to the maternal side. The development of the lacunar system leads to the division of the placenta into several compartments. The embryonically oriented part of the trophoblast will become the chorionic plate, the lacunae will develop into the intervillous space (Fig. 1), while the trabeculae will become the anchoring villi, with the growing branches developing into floating villi. Finally, the maternally oriented part of the trophoblast will develop into the basal plate. ${ }^{3}$

At day 12 after conception, the process of implantation is completed. The developing embryo with its surrounding extraembryonic tissues is totally embedded in the endometrium and the syncytiotrophoblast surrounds the whole surface of the conceptus. M esenchymal cells derived from the embryo spread over the inner surface of the trophoblast, thus generating a new combination of trophoblast and mesoderm, termed chorion. Starting on day 12 postconception, proliferation of cytotrophoblast pushes trophoblast cells to penetrate into the syncytial trabeculae, reaching the maternal side of the syncytiotrophoblast by day 14. Further proliferation of trophoblast cells inside the trabeculae (day 13) stretches the trabeculae resulting in the development of syncytial side 

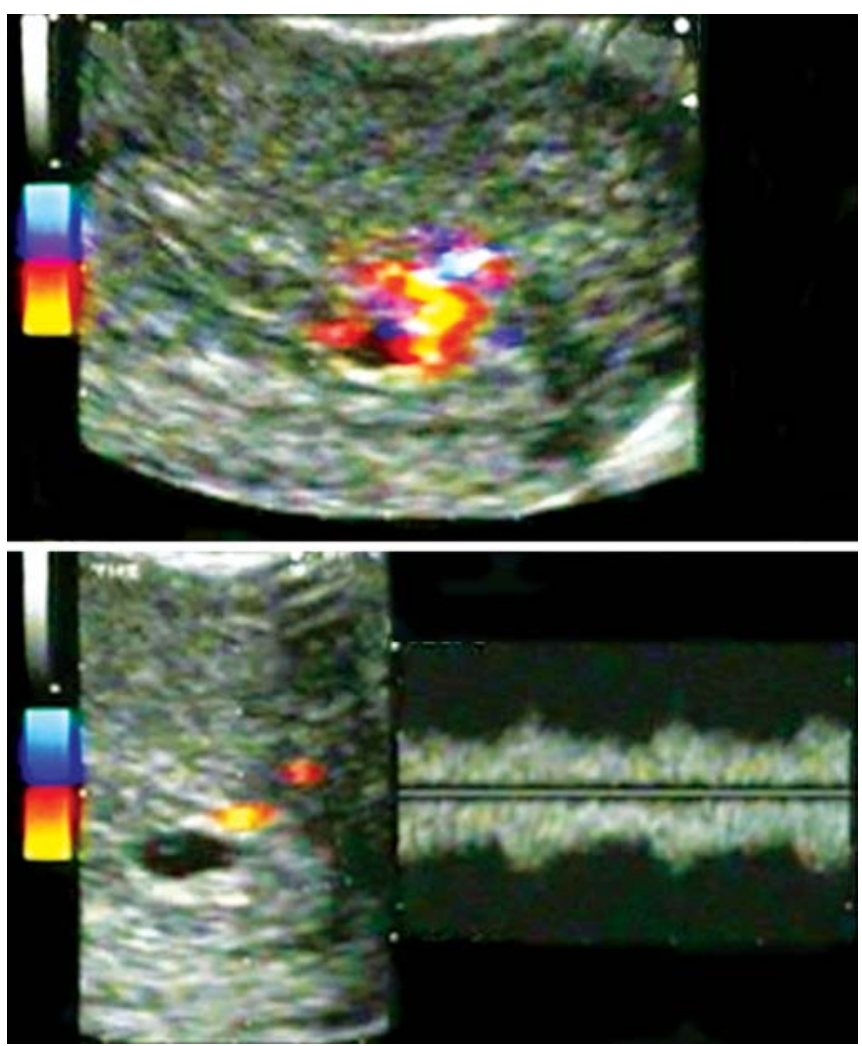

Fig. 1: Image recorded by 2D color Doppler sonography, showing intervillous blood flow

branches filled with cytotrophoblast cells (primary villi). Shortly after, the mesenchymal cells from the extraembryonic mesoderm too follow the cytotrophoblast and penetrate the trabeculae and the primary villi, thus generating secondary villi. At this stage there is always a complete cytotrophoblast layer between the penetrating mesenchyme and syncytiotrophoblast. A round day 20 and 21 , vascularization within the villous mesenchyme gives rise to the formation of the first placental vessels (tertiary villi). O nly later, the connection to the fetal vessel system will be established. The villi are organized in villous trees that cluster together into a series of spherical units known as lobules or placentones. Each placentone originates from the chorionic plate by a thick villous trunk stemming from a trabecula. Continuous branching of the main trunk results in daughter villi mostly freely ending in the intervillous space. $^{3}$

In normal pregnancies, decidual and myometrial segment of the spiral arteries (Fig. 2), undergo changes to convert them into large vessels of low resistance (Figs 3 and 4). T wo types of migratory cytotrophoblast cause thisendovascular and interstitial cytotrophoblast. Endovascular cytotrophoblast invades spiral arteries on the decidua and myometrium and replaces arterial endothelium, destroying muscle and elastic tissues in the tunica media. Interstitial cytotrophoblast destroys the ends of decidual blood vessels,

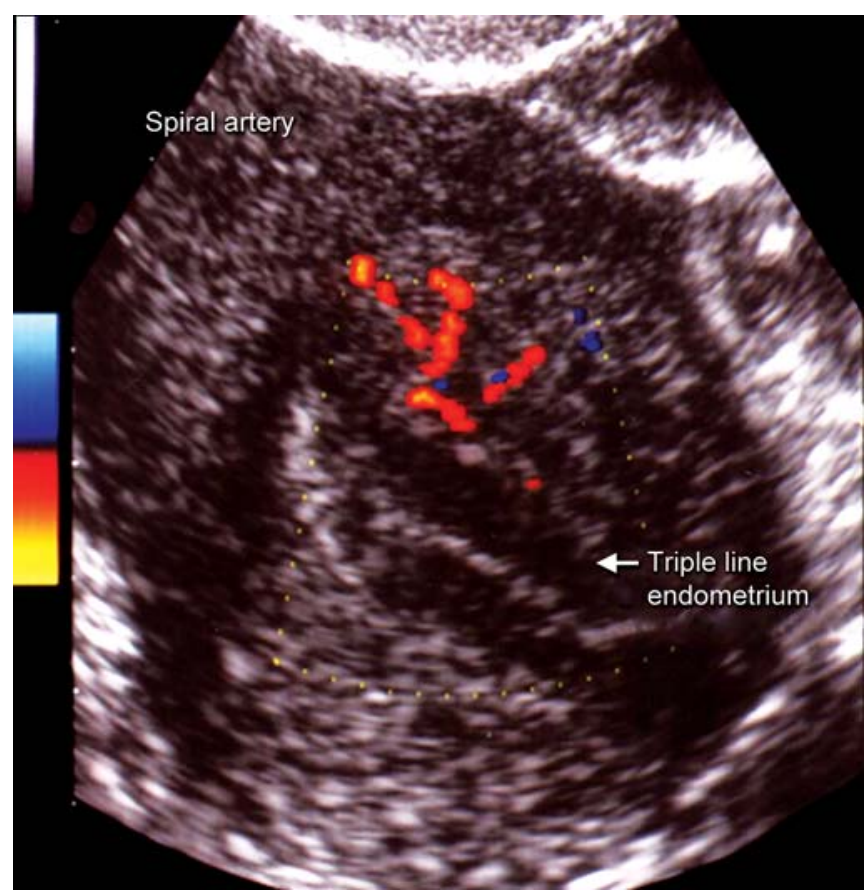

Fig. 2: Image recorded by 2D color Doppler sonography showing blood flow in spiral arteries

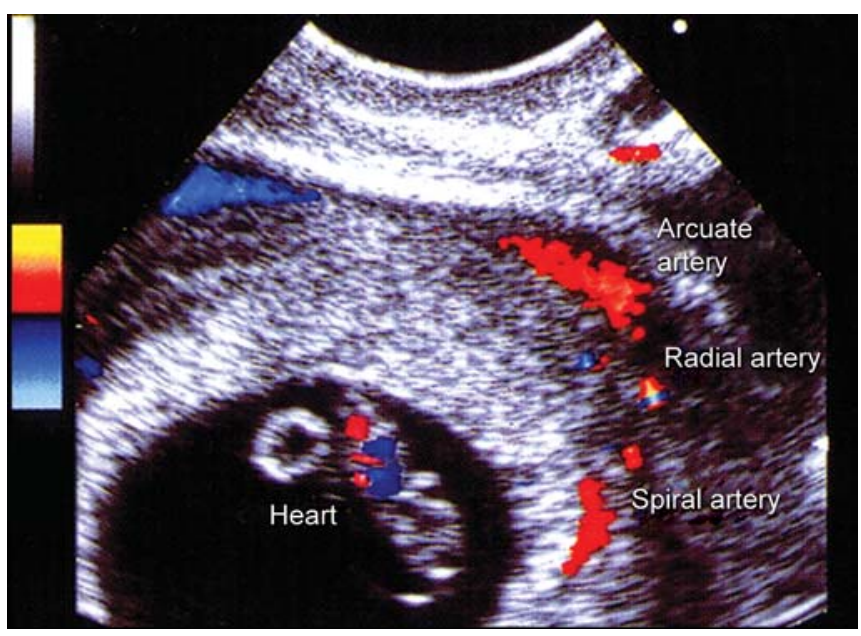

Fig. 3: Image recorded by 2D color Doppler sonography showing blood flow in part of uteroplacental circulation (arcuate, radial and spiral arteries). The terminal segments of spiral arteries will be remodelated by trophoblast cell invasion

promoting the flow of blood into the lacunae. The maternal arteries are opened up and functionally denervated so that they are completely dilated and unresponsive to circulatory pressor substances or autonomic neural control. B ehind this, at uterine radial artery level, local prostacyclin maintains vasodilatation. ${ }^{1}$ Free transfer of maternal blood to the intervillous space is established at the end of the first trimester of pregnancy. ${ }^{3}$

\section{ABNORMAL PLACENTAL DEVELOPMENT AND ULTRASOUND}

Trophoblast invasion is a key process during human placentation. Failure of trophoblast invasion and spiral artery 


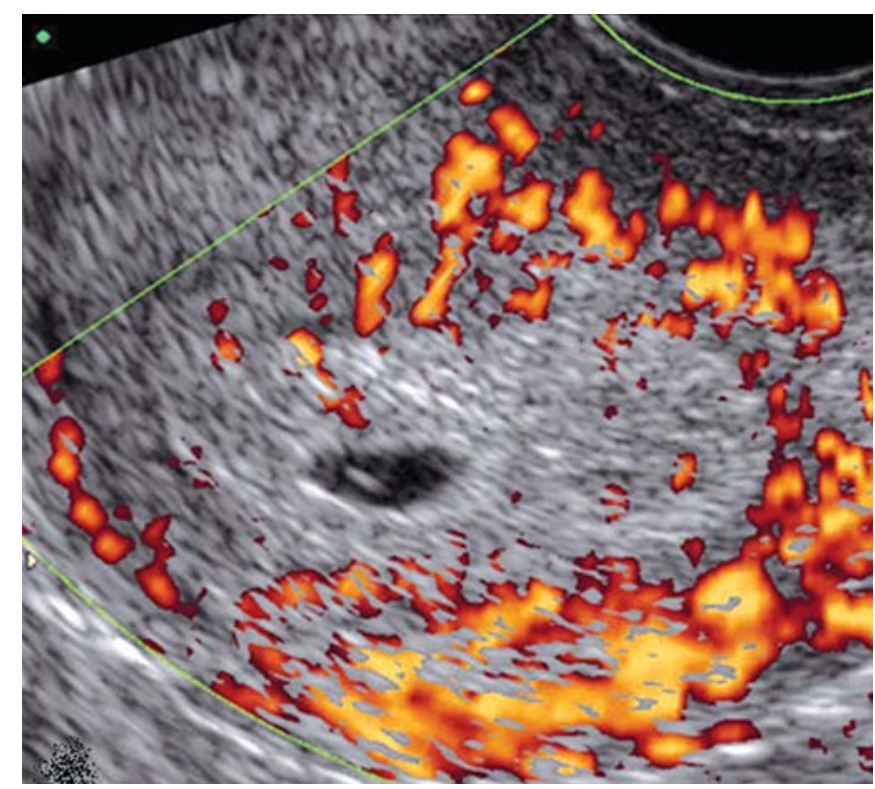

Fig. 4: Image recorded by 2D power Doppler sonography showing increased blood flow that surrounds the gestational sac as a direct consequence of the spiral arteries dilation

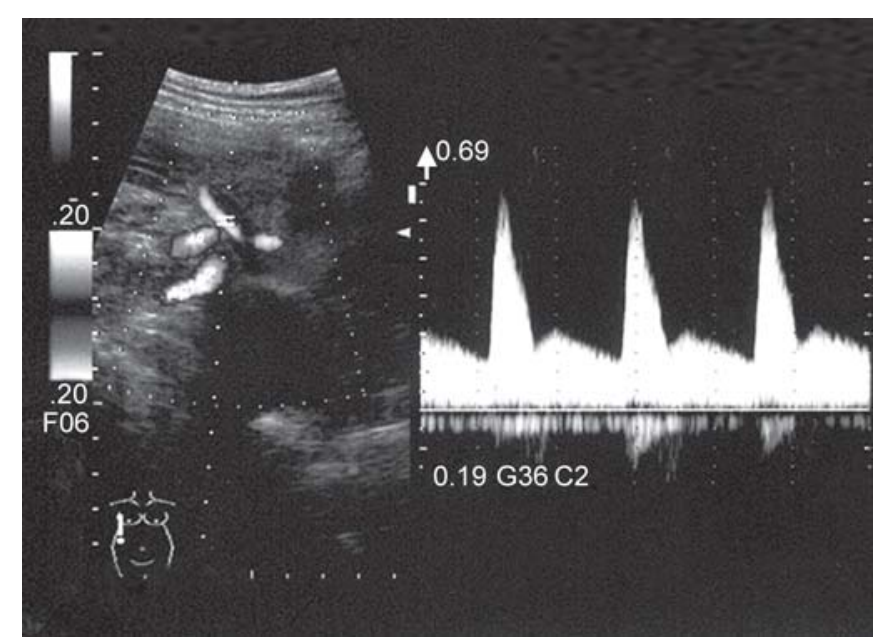

Fig. 5: Image recorded in the 30th week of gestation showing increased impedance to flow in the uterine artery with early diastolic notching

transformation leads to reduced perfusion of the placenta and fetus, and inadequate fetal nutrition and oxygenation. This condition is called uteroplacental insufficiency because the metabolic demands of the fetus and placenta exceed the uteroplacental transport capacity. It is considered that there are two phases of trophoblast invasion. The first wave of trophoblastic invasion converts the decidual segments of the spiral arteries between 6 and 10 weeks of the pregnancy. The second wave converts the myometrial segments between 14 and 16 weeks of the pregnancy. ${ }^{2}$ As a result of these physiological changes, the diameter of the spiral arteries increase from 15 to $20 \mathrm{~mm}$ to 300 to $500 \mathrm{~mm}$, reducing impedance to flow and optimizing fetomaternal exchange in the intervillous space. ${ }^{4}$ In pregnancies complicated by pre-eclampsia and IUGR, trophoblast

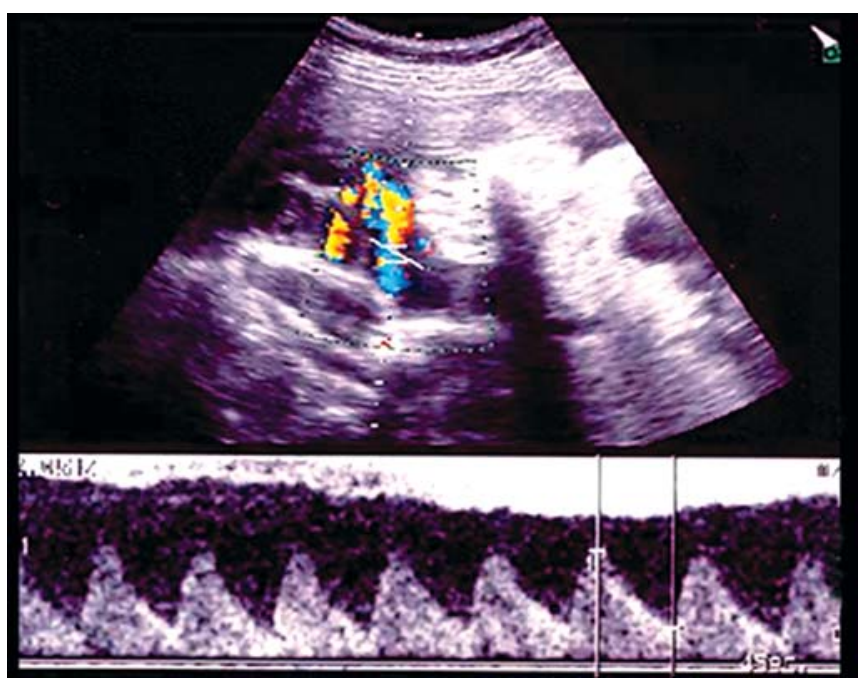

Fig. 6: Normal Doppler waveforms from the umbilical artery

invasion is limited to the decidualized endometrium, which results in failure of the spiral arteries to become lowresistance vessels. ${ }^{5}$ U sing Doppler ultrasound, uteroplacental and fetal vessels conversion of the uterine spiral arteries and placental development may be assessed.

Successful trophoblast invasion results in loss of early diastolic notching in the uterine artery Doppler waveform by the end of the first trimester. ${ }^{6,7}$ The failure to undergo physiological trophoblastic vascular changes is reflected by the high impedance to the blood flow at the level of the uterine arteries and with the characteristic waveform of early diastolic notching (Fig. 5). In normal pregnancies, due to progressive maturation of the placenta, impedance to flow in the umbilical artery decreases and end-diastolic velocity establishes by the end of the first trimester. Doppler indices continue to fall toward term as umbilical blood flow resistance decreases ${ }^{6-8}$ (Fig. 6). In cases of placental insufficiency, because of inadequate ramification of villi and increased degradation due to degenerative processes, surface of the capillary network is reduced and blood flow resistance in the placenta is elevated. These conditions reflect in the abnormal umbilical artery blood velocity waveforms. However, pathological studies have demonstrated that increased impedance in the umbilical arteries becomes evident only when at least $60 \%$ of the placental vascular bed is obliterated. ${ }^{9}$ In pregnancies with reversed or absent end-diastolic flow in the umbilical artery, compared to those with normal flow, mean placental weight is reduced and the cross-sectional diameter of terminal villi is shorter. ${ }^{10} \mathrm{~A}$ bsent diastolic velocity or retrograde diastolic velocity in the umbilical artery indicate extremely increased placental vascular impedance (Fig. 7).

Endangered by placental insufficiency, fetus activates compensatory mechanisms. Fetal response to placental dysfunction evolves from early compensatory reactions to late decompensation in multiple organ systems. ${ }^{11}$ Fetal 


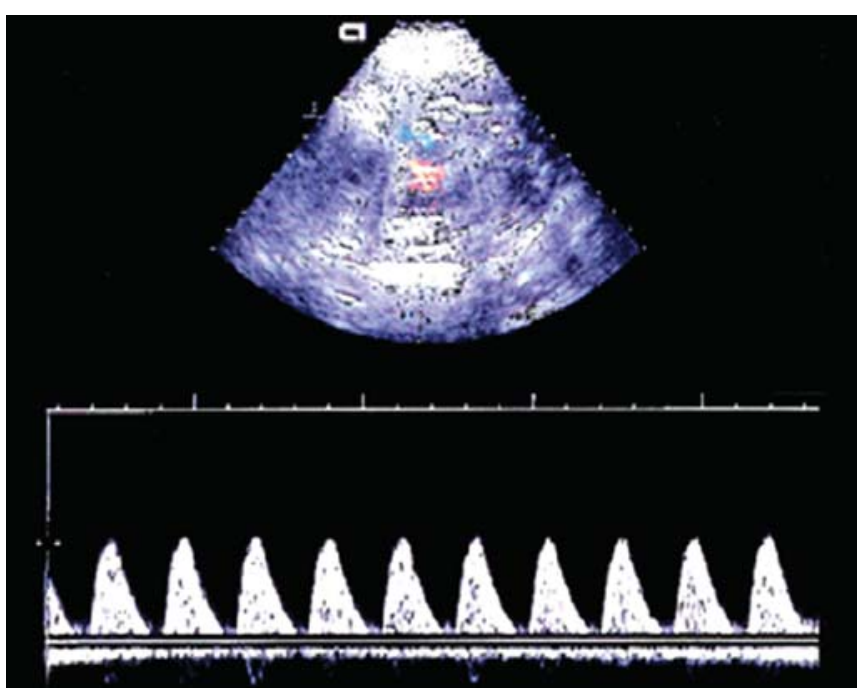

Fig. 7: Increased impedance to flow in the umbilical artery with an absent end-diastolic flow

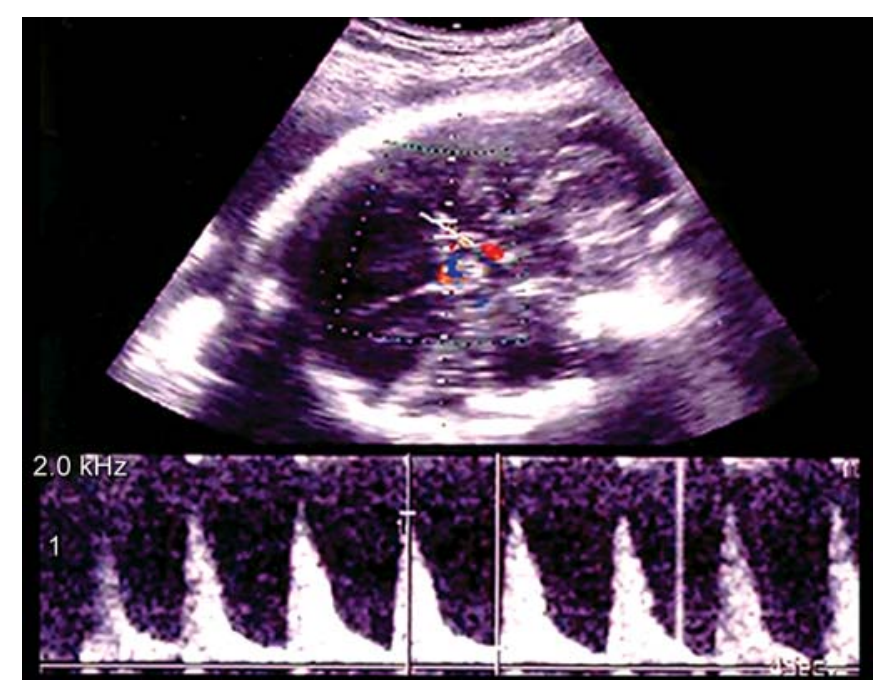

Fig. 8: Normal flow of the middle cerebral artery in the third trimester

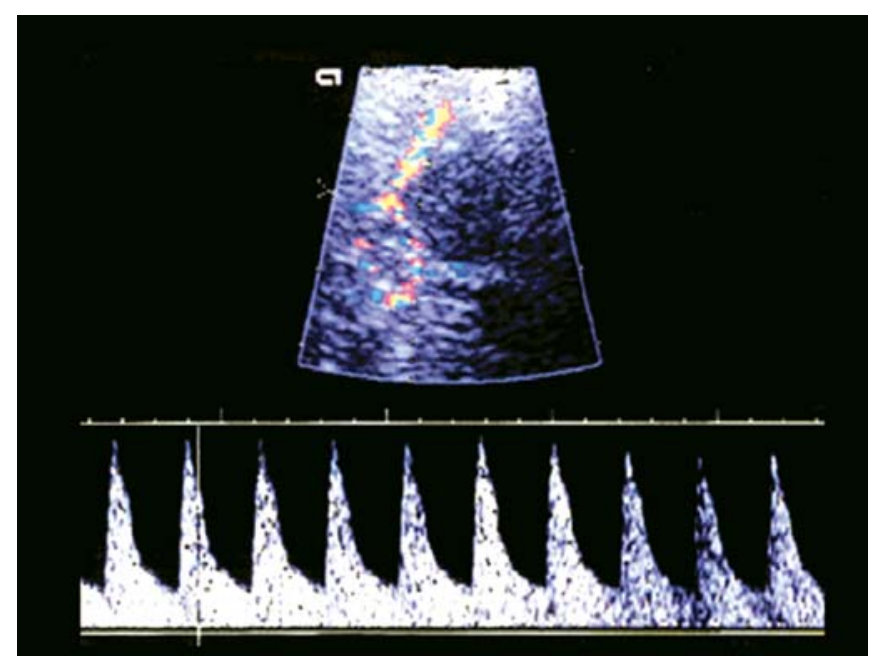

Fig. 9: Decreased impedance to flow in the middle cerebral artery ('brain-sparing effect')

hypoxia activates a range of biophysical, cardiovascular, endocrine and metabolic responses. Fetal cardiovascular responses to hypoxia, which include modification of the heart rate, an increase in arterial blood pressure and redistribution of the cardiac output toward vital organs, are probably the most important adaptive reactions responsible for maintaining fetal homeostasis. ${ }^{12}$ The redistribution of blood flow toward the fetal brain is known as the "brainsparing effect' (Figs 8 and 9). Doppler assessment of the fetal cerebral and umbilicoplacental circulations can detect fetal blood flow redistribution toward the brain during hypoxia and quantify the degree of this redistribution using the $\mathrm{C} / \mathrm{U}$ ratio. ${ }^{12-14}$ In normal pregnancies, cerebral vascular resistance remains higher than placental vascular resistance. Therefore, the cerebroumbilical $(C / U)$ ratio, expressed as the cerebral resistance index/the umbilical remains resistance index, remains higher than 1 . This ratio becomes less than 1 in case of blood flow redistribution in favor of the fetal brain. ${ }^{13}$ Previous experimental studies on animal models have shown that the $C / U$ ratio decreases in proportion to fetal $\mathrm{pO}_{2}$. 12,15

Although, the brain-sparing effect attempts to compensate for the reduced oxygen delivery to the fetal brain, it has recently become clear that this phenomenon cannot al ways prevent the development of brain lesions. ${ }^{15-17}$ O ur studies have demonstrated the existence of several phases in the hemodynamic response of the fetal brain to chronic hypoxia. During the early phase of Doppler surveillance, cerebrovascular variability was still observed; this was followed by a loss of cerebrovascular variability and finally an increase in cerebrovascular resistance with a reduction in brain perfusion. Maximal redistribution of blood flow in favor of the fetal brain was reached 5 to 8 days prior to the onset of fetal heart rate abnormalities. ${ }^{16,18}$

\section{FUNCTIONS OF THE PLACENTA}

The placenta has multiple roles in fetal metabolism and growth. The major function of the placenta is to provide diffusion of nutrients and oxygen from the mother's blood into the fetus's blood and diffusion of excretory products from the fetus back into the mother. ${ }^{19}$ The placenta also produces hormones that affect fetal growth. The placenta is usually fully formed and functional as a nutritive, respiratory, excretory and endocrine organ by the end of the third month of pregnancy. However, well before this time, oxygen and nutrients are diffusing from maternal to embryonic blood, and embryonic metabolic wastes are passing in the opposite direction. ${ }^{20}$ Most of the early nutrition is due to trophoblastic digestion and absorption of nutrients from the endometrial deciduas. This is the only source of nutrients for the embryo during the first week after implantation. The embryo continues to obtain at least 


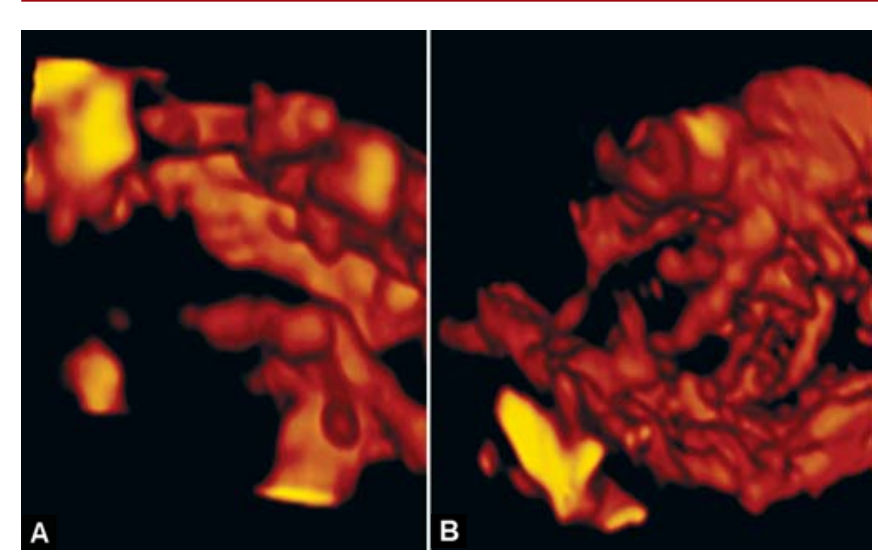

Figs 10A and $B$ : 3D power Doppler angiography of the placental vascular tree at the (A) 16th week of pregnancy and at the (B) 36th week of pregnancy

some of its nutrition in this way for another 8 weeks, although the placenta also begins to provide nutrition after about the 16th day after fertilization (a little more than 1 week after implantation). ${ }^{19} \mathrm{M}$ olecules of low molecular weight, such as blood gases, sodium, water, urea, fatty acids, nonconjugated steroids, pass through placental membrane by simple diffusional exchange between the circulations. Hexose sugars, conjugated steroids, amino acids, nucleotides, water-soluble vitamins, plasma proteins, cholesterol will not gain access to the fetal circulation unless either special transport mechanisms exist or the integrity of the barrier is breached. ${ }^{21}$ In the early months of pregnancy, the placental membrane is still thick because the placenta is not fully developed. Therefore, its permeability is low. Further, the surface area is small because significant placental growth has not occurred yet. In later pregnancy, the permeability increases due to the thinning of the membrane diffusion layers and the multiple expansion of the surface area, giving way to a tremendous increase in placental diffusion (Figs $10 \mathrm{~A}$ and $\mathrm{B}$ ). ${ }^{19}$ In addition to the placental thickness, the factors that will influence exchange between the mother and the fetus include the maternal and the fetal blood flow; the fetal and the maternal concentrations of the substances to be transported; and the types of transport mechanisms available. The exchange of more freely diffusible molecules such as $\mathrm{O}_{2}$ is to a larger extent dependent on the blood flow than placental thickness. ${ }^{21}$

\section{Fetal Growth and Metabolism}

As soon as within the 1st month following the fertilization of the ovum, all the organs of the fetus have al ready begun to develop and in the next 2 to 3 months, the fine anatomic structures of the organs will be formed. A fter the 4th month, the organs of the fetus, including the majority of their substructures, are for the most part the same as those of the neonate. However, the development of the cells in the structures is still far from complete and will require the remaining 5 months of pregnancy to complete devel opment. ${ }^{19}$

Normal fetal growth requires macronutrientscarbohydrates, lipids, proteins and micronutrientsvitamins and minerals. A Iso, other factors influence grow th, like grow th factors and hormones. The main ingredient of the fetal diet is carbohydrate. The fetus has a low capacity for gluconeogenesis, largely because the necessary enzymes, although present, are inactive due to a low fetal arterial $\mathrm{pO}_{2}$. The fetus must therefore obtain its glucose from the maternal blood. ${ }^{21}$ The growing fetus requires approximately $87 \mathrm{kcal} /$ $\mathrm{kg} /$ per day. ${ }^{22}$ A bout half of the calories needed for fetal growth and metabolism come from the mother's glucose, and the other half from her amino acids and placental lactate. ${ }^{21}$ The fetus has a high ability of storing proteins and fats. ${ }^{19}$ Protein accumulation occurs early in fetal development, to reach its maximum by week 35 . Protein deposition precedes fat deposition. ${ }^{21}$ Fetal fat content is low at 26 weeks. Fat acquisition starts sometime between the 26 and 32 weeks and continues intensively thereafter, being a result of glucose utilization rather than placental fatty acid uptake. ${ }^{22}$ By term, about three times as much energy is stored as fats than as proteins. In addition, glucose is also stored as glycogen in the fetal liver. Glycogen is an important nutrient in the period immediately after birth, before nutrients from breast milk are used. ${ }^{21}$

Fetal metabolism shows some particularity in relation to calcium, phosphate, iron, and some vitamins. A bout $22.5 \mathrm{gm}$ of calcium and $13.5 \mathrm{gm}$ of phosphorus are accumulated in an average fetus during gestation. A bout one-half of these accumulate during the last 4 weeks of gestation, which is coincident with the period of rapid ossification of the fetal bones and with the period of rapid weight gain of the fetus. I ron accumulates in the fetus even more rapidly than cal cium and phosphate. M ost of the iron is in the form of hemoglobin, which begins to be formed as early as in the third week after fertilization of the ovum. Small amounts of iron are concentrated in the mother's uterine progestational endometrium even before implantation of the ovum. This iron is used to form the early red blood cells. A bout one-third of the iron in a fully developed fetus is normally stored in the liver. Interestingly, the fetus needs an equal intake of vitamins as the adult. The $B$ vitamins, especially vitamin $B_{12}$ and folic acid, are necessary for formation of red blood cells and the nervous tissue, as well as for the overall grow th of the fetus. V itamin $C$ is necessary for appropriate formation of intercellular substances, especially the bone matrix and fibers of connective tissue. $V$ itamin $D$ is needed for normal bone growth in the fetus. The mother needs it for adequate 
absorption of calcium from her gastrointestinal tract. If the mother has plenty of this vitamin in her body fluids, large quantities of the vitamin will be stored by the fetal liver to be used by the neonate for several months after birth. Vitamin $E$, although the mechanisms of its functions are not clear, is necessary for normal development of the early embryo. In its absence in laboratory animals, spontaneous abortion usually occurs at an early stage of pregnancy. $\mathrm{V}$ itamin $\mathrm{K}$ is used by the fetal liver for formation of blood coagulation factors. Prenatal storage in the fetal liver of vitamin $\mathrm{K}$ derived from the mother is helpful in preventing fetal hemorrhage, particularly hemorrhage in the brain when the head is traumatized by squeezing through the birth canal. ${ }^{19}$

The fetus actively participates in endocrine regulation of its metabolism and growth by synthesis and secretion of hormones. For instance, the rate at which glucose is utilized by growing fetal tissues is probably determined largely by the actions of fetal insulin. The storage of glucose as fat is also regulated primarily by fetal insulin. Fetal adrenocorticotropic hormone (ACTH) and glucocorticoids stimulate the storage of glucose as glycogen. ${ }^{21}$ Hormonal regulation of fetal growth differs from hormonal regulation of growth during postnatal life. Furthermore, fetal growth hormone $(\mathrm{GH})$ has a small role in stimulating fetal growth. A lthough pituitary begins to produce and secrete $\mathrm{GH}$ during the 5th week of gestation, fetal GH does not significantly affect fetal growth, possibly due to the lack of functional $\mathrm{GH}$ receptors on fetal tissues. ${ }^{23}$ Data have shown that pituitary aplasia and congenital hypopituitarism do not cause severe IU GR. ${ }^{24,25}$ On the contrary, fetal insulin significantly stimulates fetal growth. It is a known fact that pancreatic agenesis is associated with severe growth restriction ${ }^{26}$ and that fetal hyperinsulinemia leads to fetal mass overgrow th. It is believed that insulin-like growth factors (IGFs or somatomedins) produced by a large range of fetal cell types and particularly by the fetal liver, provide a major endocrine stimulus to fetal growth. ${ }^{21}$ They have the potent effect of increasing all aspects of bone growth in postnatal life. ${ }^{19}$ IGFs are present in human fetal tissue extracts after 12 weeks gestation. ${ }^{22}$ IGF-1 has the most important role in stimulation of fetal growth. ${ }^{21}$ Its levels in fetal and cord circulation directly correlate with the fetal length and mass. ${ }^{27}$ R educed plasma concentration of IGF-1 has been reported in intrauterine growth restriction (IUGR). ${ }^{28}$ Furthermore, maternal starvation leads to a rapid decrease in fetal plasma IGF-1 concentration, which is generally associated with the cessation of intrauterine growth. ${ }^{29}$ It is considered that glucose is the major regulator of fetal IGF-1 secretion. ${ }^{30}$ M aternal IG F-1, IGF-2 and insulin do not cross the placenta, and do not have a direct effect on fetal growth, but may have an effect on placental function, thus altering the nutrient exchange between the placenta and the fetus. ${ }^{31}$ It has been found that maternal plasma IGF-1 concentration correlates with fetal growth. ${ }^{32}$ Production of fetal IGFs is stimulated by prolactin, insulin and human chorionic somatomammotropin (HCS). ${ }^{33}$ In the fetus, HCS acts via lactogenic receptors to stimulate growth, regulate intermediary metabolism and stimulate the production of IGFs, insulin, adrenocorticotropic hormones and pulmonary surfactant. ${ }^{23}$ Fetal thyroid hormones also stimulate growth, especially in the later stage of pregnancy, but their most significant role is the one they have in the central nervous system development. ${ }^{21}$

A dditional factors that affect birth weight include parity (primiparous mothers have smaller babies than multiparous mothers), maternal size, multiple pregnancy. ${ }^{21} \mathrm{M}$ aternal nutrition is also of great significance for fetal growth and the adverse effects of severe mal nutrition on fetal well-being and neonatal survival have been long known. Recent data have confirmed a great impact of maternal diet during pregnancy on fetal growth and development, as well as on postnatal development and health. ${ }^{34-43}$ It is during intrauterine life that the diet has significant effect on the brain development. It has been known for some time that folic acid plays a protective role in neurodevelopmental processes. Periconceptional use of folic acid has been proven to significantly reduce the risk of neural tube birth defects. ${ }^{34}$ Such, birth defects can cause death or permanent physical disability. Periconceptional use of folic acid decreases the occurrence of anencephaly and spina bifida by at least $50 \% .{ }^{35} \mathrm{H}$ ence, some countries (USA, Canada) have decided to fortify food with folic acid. A recent study on the preval ence of congenital abnormalities following folic acid fortification of grain in the United States found a modest, yet statistically significant decrease in prevalence of transposition of the great arteries, cleft palate, pyloric stenosis and omphalocele. ${ }^{35} \mathrm{Y}$ et, other studies provide no evidence of folate being an important factor in the prevention of birth defects other than neural tube defects. ${ }^{36}$ Furthermore, a significant protective effect was seen with large doses of folic acid (approximately $6 \mathrm{mg} / \mathrm{d}$ ) and iron (150$300 \mathrm{mg} / \mathrm{d}$ of ferrous sulfate) during the first gestational month against D own's syndrome. ${ }^{37}$

Numerous findings have shown a favorable impact of essential fatty acids on prenatal development. ${ }^{38-40,42,43}$ O mega- 3 and omega- 6 fatty acids are necessary for human growth and development. Since, their endogenous synthesis is impossible, they need to be taken into the body through diet. The arachidonic (AA) and docosahexanoic acids 
(DHA) are the key components of all membranes and are incorporated into the structural lipids of the developing brain. Fetal demand for essential fatty acids is at its peak during the third trimester of pregnancy. ${ }^{21} \mathrm{~A}$ recent study has demonstrated that DHA supplemented during pregnancy plays a role in the maturation of the visual system and benefits infant visual acuity at 4 but not 6 months of age. ${ }^{38}$ A Iso, results of a recent study indicate that DHA consumption in pregnancy significantly affects problem solving abilities at the age of 9 months, but does not affect memory processes. ${ }^{39}$ Additionally, children's mental processing scores at 4 years of age correlated significantly with maternal intake of DHA during pregnancy. ${ }^{40}$ Seafood (especially sardine and tuna) is a rich source of omega-3 fatty acids. Essential fatty acids can be al so found in linseed oil, walnut oil and soy. In the USA, women are advised to limit their seafood intake during pregnancy to $340 \mathrm{gm}$ per week. A ccording to a recent study published in an esteemed journal, maternal seafood consumption should be more than $340 \mathrm{gm}$ per week. A lower seafood intake during pregnancy was in the study associated with an increased risk of suboptimum devel opmental outcome. ${ }^{41}$ Further, the findings suggest a protective effect of fish intake during pregnancy against the risk of atopy and asthma. ${ }^{42}$ Consumption of apples during pregnancy may also have a protective effect against the development of childhood asthma and allergic diseases. ${ }^{43}$

Healthy and varied diet during pregnancy is required for normal fetal growth and development. M ost pregnant women need 2200 to $2900 \mathrm{kcal}$ a day. ${ }^{44}$ If appropriate nutritional elements are not present in a pregnant woman's diet, a number of maternal deficiencies can occur, especially in calcium, phosphates, iron and vitamins. ${ }^{19}$

\section{Fetal Cardiovascular System}

The cardiovascular system is the first embryonic system to start functioning. The need for substrates which facilitate fast growth and development of the embryo requires an early development of the mechanism that supplies the cells with nutrients and removes the metabolic products from them. Cardiovascular development begins when the process of diffusion becomes inadequate to supply the fetus with nutrients and oxygen. Blood circulation can be observed in the 'body' of the embryo as early as at the end of the third week of the intrauterine life. ${ }^{45}$

Between the 27 and 35th day of intrauterine life, during which the embryo grows from $5 \mathrm{~mm}$ in length to about 16 to $17 \mathrm{~mm}$, cardiac septum and endocardial cushions begin to form. The endocardial cushions will give rise to mitral and tricuspid valves. By the end of 7th week, they are short

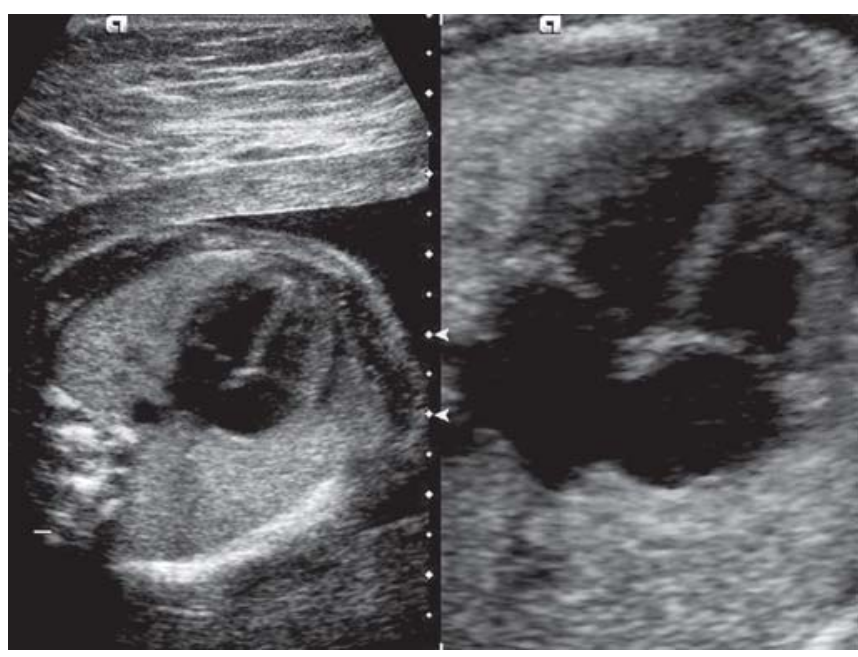

Fig. 11: Four-chamber view of the fetal heart

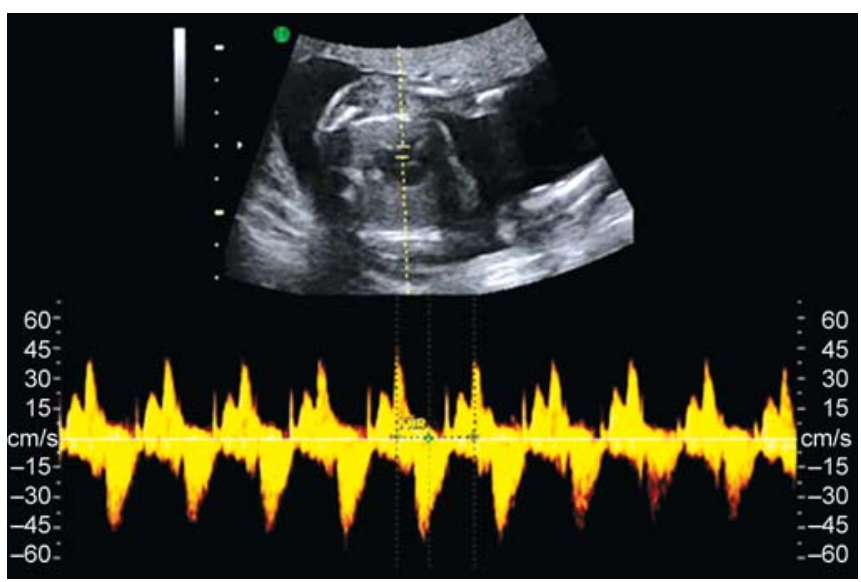

Fig. 12: Fetal cardiac activity with a heart rate of $150 \mathrm{bpm}$

and thick, but over the next few weeks they are becoming longer and thinner, and achieve their final shape. Impairments in cardiac septum development lead to the existence of pathological communication between the heart chambers (Fig. 11), which can be more or less lifethreatening condition for newborn child. Some of these anomalies, such as ventricular septal defect, are among common congenital anomalies and can occur independently or as a part of different syndromes. ${ }^{46,47}$ Fetal echocardiography is a powerful tool and many cardiac malformations can be successfully diagnosed before birth.

The human heart starts beating between the 21 and 23rd day after fertilization, at a heart rate of 65 beats $/ \mathrm{min}^{4}{ }^{4}$ In that period, the heart is a tube-like structure with a single lumen. B etween the 5 and 9 th week of gestation the heart rate accelerates from 80 beats $/ \mathrm{min}$ to 165 beats $/ \mathrm{min} .{ }^{49,50} \mathrm{It}$ has been shown that a continuous decrease in the heart rate during this period is associated with miscarriages occurring in the first trimester. ${ }^{50}$ By the 10 th week after fertilization, the heart rate has reached its highest value (approximately 
170/min), it starts decreasing (Fig. 12). Before birth, the human heart contracts at a rate of about 140 beats $/ \mathrm{min}$.

The fetal circulatory system operates much differently than the circulatory system of the newborn baby, which is not surprising considering the specific features of fetal environment. A fter the birth, the individual components of the circulatory system are in serial connection. However, the fetal circulatory system is organized in parallel circle. ${ }^{51}$ Further, fetal values of cardiac output and blood pressure are significantly different from values in adults.

During intrauterine life, blood returning from the placenta through the umbilical vein passes through the ductus venosus, mainly bypassing the liver. Then most of the blood entering the right atrium from the inferior vena cava is directed in a straight pathway across the posterior aspect of the right atrium and through the foramen ovale directly into the left atrium. Thus, the well-oxygenated blood from the placenta enters mainly the left side of the heart, rather than the right side and is pumped by the left ventricle mainly into the arteries of the head and forelimbs. The blood entering the right atrium from the superior vena cava is directed downward through the tricuspid valve into the right ventricle. This blood is mainly deoxygenated blood from the head region of the fetus and it is pumped by the right ventricle into the pulmonary artery. Since, the pressure in the pulmonary artery is about $0.7 \mathrm{kPa}$ higher than the pressure in the aorta, almost all the blood from the pulmonary artery goes through the arterial duct (ductus B otallijev) into the descending aorta, then through the two umbilical arteries into the placenta, where the deoxygenated blood becomes oxygenated. Only a small portion of blood from the descending aorta portion goes to the visceral organs and lower extremities. ${ }^{19}$

Blood carrying the highest oxygen saturation goes to the fetal heart, the brain, the upper extremities while the other parts of fetal body receive blood with lower oxygen saturation. Also, fetal blood $\mathrm{pO}_{2}$ is much lower than maternal blood $\mathrm{pO}_{2}$. At term $\mathrm{pO}_{2}$ of fetal blood after the oxygenation in the placenta amounts $30 \mathrm{~mm} \mathrm{Hg}^{2}$ Such, low $\mathrm{pO}_{2}$ levels can be observed in adults at altitudes between 6000 and 8000 meters, at which human life is barely possible. Therefore, fetal environment has long been considered the Mount Everest in utero. ${ }^{52}$ Despite the low $\mathrm{pO}_{2}$ in the fetal blood, the fetus does not live in hypoxic environment. Due to adaptive mechanisms, the amount of oxygen delivered to the fetal tissue is similar to the amount of oxygen delivered to maternal tissue by maternal blood. ${ }^{19}$ In addition, the hemoglobin concentration of fetal blood is about $50 \%$ greater than that of the mother. Furthermore, fetal hemoglobin can carry more oxygen at a low than it can at a high $\mathrm{pCO}_{2}$. The fetal blood entering the placenta carries large amounts of carbon dioxide, but much of this carbon dioxide diffuses from the fetal blood into the maternal blood. L oss of the carbon dioxide makes the fetal blood more alkaline, whereas the increased carbon dioxide in the maternal blood makes it more acidic. These changes cause the capacity of fetal blood to combine with oxygen to increase and that of maternal blood to decrease. This forces more oxygen from the maternal blood, while enhancing oxygen uptake by the fetal blood. Thus, the B ohr shift operates in one direction in the maternal blood and in the other direction in the fetal blood. These two effects make the Bohr shift twice as important here as it is for oxygen exchange in the lungs; therefore, it is called the double B ohr effect. These mechanisms, as well as a large cardiac output, ensure adequate supply of oxygen of fetal tissues, despite its low partial pressure. ${ }^{19}$

$M$ aintenance of normal cardiovascular function, blood pressure, heart rate and the flow distribution through the placenta and fetal tissue are influenced by the local vascular and reflex mechanisms. Further, the autonomic nervous system and hormones also have an effect on the fetal heart and circulation. The potential regulators can be identified by measuring their concentration and dynamics of secretion in states in which a redistribution of the blood flow occurs, such as fetal hypoxia. The first line of supervision over the circulation of the fetus are the carotid chemoreceptors, but not the aortic chemoreceptors. They mediate the fetal cardiovascular response (redistribution of circulation in favor of vital organs like the heart, brain and adrenal glands to acute hypoxemia)..$^{53}$ Slower regulators, the second line of control, are hormones antidiuretic hormone (ADH), angiotensin $\mathrm{II}$, catecholamines and cortisol. ${ }^{54-56} \mathrm{ADH}$ and angiotensin II are released independently of the carotid chemoreceptors, whereas the secretion of cortisol and catecholamines is partially under the control of these neural mechanisms. After carotid sinus denervation or splanhic blockade, rapid secretion of cortisol in response to hypoxia or a sudden drop in blood pressure, is decreased. While the secretion of ACTH does not change and occurs about 15 minutes after stimulation. ${ }^{57,58}$ Thus, the rapid rise in cortisol secretion is the result of neural mechanisms and not as a result of ACTH stimulation. However, the role and purpose of such regulation is unclear. Medullary, hypothalamic and cerebral cortical activity also affect fetal cardiovascular function. ${ }^{59}$ Furthermore, in control of fetal circulation autocrine and paracrine mechanisms play important role. Some of the possible regulators of the peripheral resistance, at least in the sheep fetuses, are endothelin-1 and nitrogen-(II)-oxide (NO) ${ }^{60,61}$ They allow 
an increase of cerebral flow in fetal hypoxia. Several other factors, such as sleeping of the fetus or uterine contractions, can also have a temporary influence on the cardiovascular system. $^{62}$

One of the most important events after the delivery is the adjustment of the circulation of new conditions. The transitional period of circulation, which lasts 4 to 12 hours after birth, is characterized by a large increase of the blood flow through the lungs and by the establishment of the pulmonary circulation. The primary change in the circulation at birth is loss of the tremendous blood flow through the placenta, which approximately doubles the systemic vascular resistance at birth. This increases the aortic pressure as well as the pressures in the left ventricle and left atrium. Furthermore, in the unexpanded fetal lungs, the blood vessels are compressed because of the small volume of the lungs. A fter birth, the pulmonary vascular resistance greatly decreases as a result of expansion of the lungs. Also, in fetal life, the hypoxia of the lungs causes considerable tonic vasoconstriction of the lung blood vessels but when aeration of the lungs eliminates the hypoxia, the capillary endothelial cells produce vasoactive substances such as NO and prostaglandin 12, which have a strong vasodilatory effect and vasodilation takes place. ${ }^{19}$ All these changes together reduce the resistance to blood flow through the lungs as much as fivefold, which reduces the pulmonary arterial pressure, right ventricular pressure and right atrial pressure. Changes in pulmonary and systemic resistances at birth cause blood now to attempt to flow from the left atrium into the right atrium, through the foramen ovale. Consequently, the small valve that lies over the foramen ovale on the left side of the atrial septum closes over this opening, thereby preventing further flow through the foramen ovale. A rterial ductus begins to close around 4 hours after birth and is usually completely closed after 24 hours. Its closing marks the end of the transitional period of the new born circulation. A fter birth, blood begins to flow backward from the aorta into the pulmonary artery through the ductus arteriosus, rather than in the other direction as in fetal life. However, after only a few hours, the muscle wall of the ductus arteriosus constricts markedly. This is called functional closure of the ductus arteriosus. Then, during the next 1 to 4 months, the ductus arteriosus ordinarily becomes anatomically occluded by growth of fibrous tissue into its lumen. The cause of ductus arteriosus closure rel ates to the increased oxygenation of the blood flowing through the ductus. In fetal life, the $\mathrm{pO}_{2}$ of the ductus blood is only 15 to $20 \mathrm{~mm} \mathrm{Hg}$, but it increases to about $100 \mathrm{~mm} \mathrm{Hg}$ within a few hours after birth. Furthermore, many experiments have shown that the degree of contraction of the smooth muscle in the ductus wall is highly related to this availability of oxygen. ${ }^{19}$ The reason for the closure of the venous duct is still unknown. Immediately after birth, blood flow through the umbilical vein ceases, but most of the portal blood still flows through the ductus venosus, with only a small amount passing through the channels of the liver. However, within 1 and 3 hours the muscle wall of the ductus venosus contracts strongly and closes this avenue of flow. A s a consequence, the portal venous pressure rises from near 0 to 6 to $10 \mathrm{~mm} \mathrm{Hg}$, which is enough to force portal venous blood flow through the liver sinuses. A lthough the ductus venosus rarely fails to close, we know almost nothing about what causes the closure. Knowing the characteristics of this transitional phase of circulation is very important because the postnatal increase of the resistance in the pulmonary capillaries, for example caused by hypoxia or respiratory distress syndrome, if exceeds the value of systemic resistance, can restore conditions as they existed in the fetal life, greater resistance in the pulmonary circulation than in systemic and pulmonary-aortic or right-left flow of blood through the arterial duct. ${ }^{19}$

\section{Fetal Gastrointestinal System, Development of Appetite and Satiety Mechanisms}

The primitive gut forms during the fourth week of the embryonic development. The primitive gut is divided into three parts: The foregut, midgut and hindgut. The derivatives of the foregut are the pharynx and its derivatives, the lower respiratory tract, the esophagus, the stomach, the duodenum, proximal to the common bile duct, and the liver, biliary tract, gallbladder, and pancreas. The derivatives of the midgut are the small intestines (except for the duodenum from the stomach (Fig. 13) to the entry of the common bile

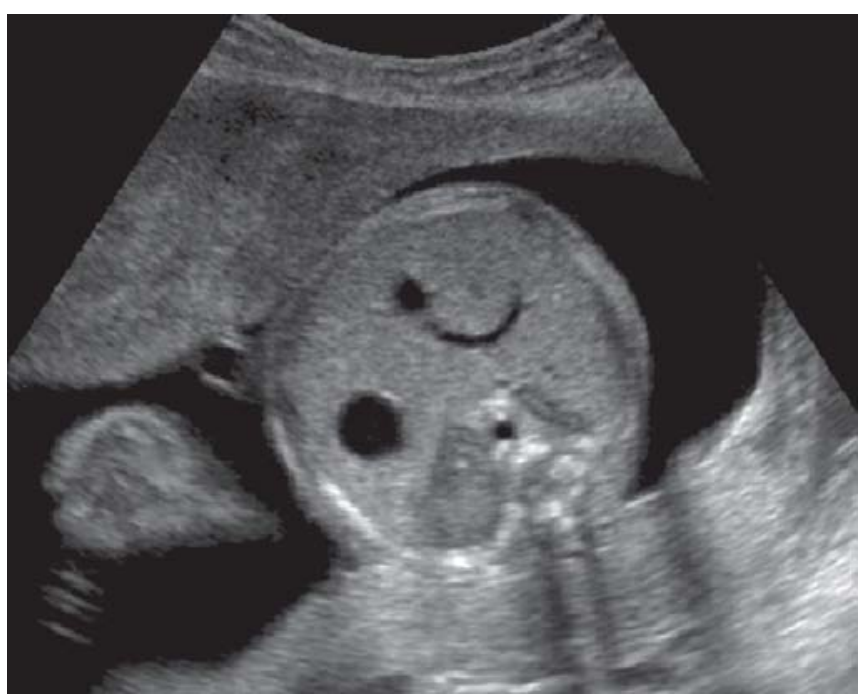

Fig. 13: Transverse scan of the fetal abdomen showing the stomach, liver and intrahepatic part of the umbilical vein 


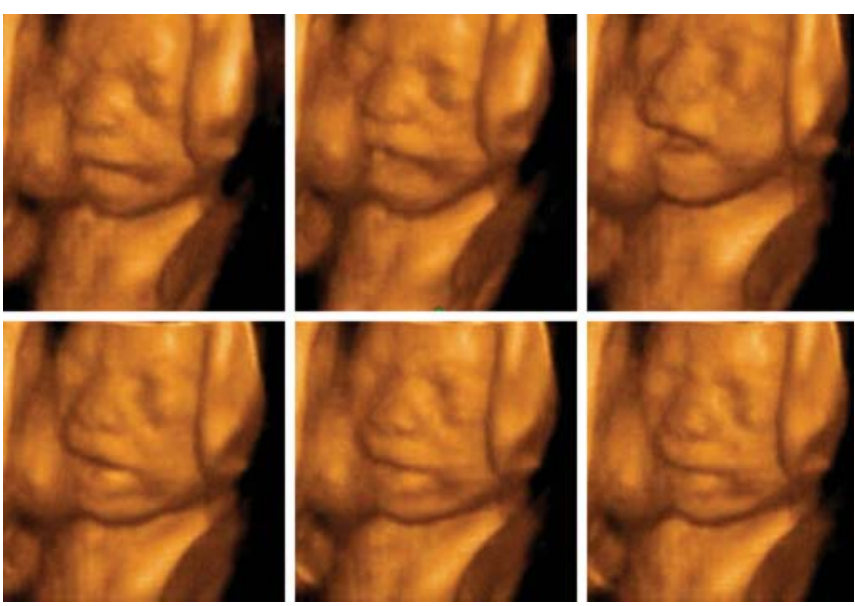

Fig. 14: A sequence of images of the fetus recorded by 4D sonography showing swallowing movements

duct), cecum and appendix, ascending colon, and proximal one-half to two-thirds of the transverse colon. The derivatives of the hindgut are the distal one-third to onehalf of the transverse colon, descending colon, sigmoid colon, rectum and upper portion of the anal canal, and part of the urogenital system. ${ }^{63} \mathrm{~A}$ ctivity of the gastrointestinal system begins during an early stage of pregnancy. By 10 weeks, peristalsis begins in the large intestine $e^{64}$ and by 11 weeks in the small intestine. ${ }^{65}$ Also, fetal swallowing activity was observed from the 11th week of gestation. ${ }^{66}$

Swallowing amniotic fluid reflects fetal CNS maturation and has numerous, although not entirely understood roles (Fig. 14). Fetal swallowing activity contributes to somatic growth, development and maturation of the fetal gastrointestinal tract. It has been estimated that swallowing of amniotic fluid proteins provides 10 to $15 \%$ of nitrogen requirements in the normal fetus. U pper gastrointestinal tract obstructions in human fetuses are associated with significantly greater occurrence of fetal growth restriction as compared with lower gastrointestinal obstructions. Studies have demonstrated that impairment of fetal swallowing in rabbits near term induces weight decrease. Esophageal ligation of ovine fetuses during midgestation induces a 30\% decrease of small intestine villus height and a reduction in the liver, pancreas and intestinal weight. ${ }^{67}$ Fetal swallowing is an important, yet not the only mechanism of amniotic fluid volume regulation. A ltered fetal swallowing has been associated with both a decrease and an increase in the amniotic fluid volume. ${ }^{68}$ These conditions are associated with a higher risk of perinatal morbidity and mortality. Furthermore, in some fetuses with esophageal atresia, the volume of amniotic fluid is increased. It is important to note that this is the case in some, but not all fetuses with esophageal atresia. Namely, this anomaly is often accompanied by tracheoesophageal fistula, a shortcut to the gastrointestinal tract. Therefore, intake of liquid during the respiratory movements might explain the nonappearance of polyhydramnios in some of these cases. ${ }^{67}$ Polyhydramnios sometimes, although not always, develops in anencephalic fetuses. Some of these fetuses have an intact swallowing reflex. Cases of a normal amniotic fluid volume and reduced fetal swallowing have also been described. A ssessment of fetal swallowing using gray-scale and color Doppler sonography has demonstrated that there is a fetal trend toward the development of more coordinated swallowrelated movements and more functional nose-mouth flow with the advancement of gestational age. These investigators have postulated that knowledge of the physiologic mechanism involving swallowing development could contribute to identification of altered swallow-related movements in fetuses with malformations of the gastrointestinal tract or with neurological disorders. ${ }^{69}$ Our recentinvestigation, performed by $4 \mathrm{D}$ ultrasound, has shown that swallowing pattern displays a peak frequency at the end of the second trimester. At the beginning of the third trimester, a decreasing incidence of this pattern was recorded. ${ }^{70}$ Some studies have shown that fetal swallowing activity may be modulated in accordance with neurobehavioral state alterations (stimulation of swallowing with shifts from quiet to active sleep). Furthermore, fetal swallowing is influenced by the volume of amniotic fluid, hypoxia, hypotension and plasma osmolality changes. ${ }^{67}$ Experiments in fetal lambs have indicated that dipsogenic mechanisms begin to regulate swallowing during intrauterine life. Swallowing and arginine-vasopressin (AVP) secretion increase, following the central adminis-tration of hypertonic saline solution and angio-tensin II. ${ }^{71,72} \mathrm{H}$ owever, the fetus seems to have an extensively reduced sensitivity to osmotic stimuli when compared to the adult, ${ }^{73-75}$ despite the intact dipsogenic nuclei. The fetus swallows about six times more liquid in comparison to the adult. M echanisms underlying the high rate of human fetal swallowing are regulated, in part, by tonic activity of central angiotensin II, glutamate $\mathrm{N}$-methyl-D-aspartate receptors and neuronal production of the nitric oxide. ${ }^{68} \mathrm{~A}$ reduced NM DA receptor expression within the forebrain dipsogenic neurons contributes to observed differences in drinking activities between the fetus/neonate and the adult. ${ }^{76}$ Reduced swallowing activity during the systemic hypotension, despite elevated renin levels in plasma, provides further evidence that the fetal dipsogenic response is markedly different from that of the adult. ${ }^{77}$ It is possible that dipsogenic responses develop in utero in the human fetus to provide thirst stimulation for appropriate water intake during the immediate neonatal period. ${ }^{67} \mathrm{~A}$ ccording to some studies, altered intrauterine osmotic environment may modulate not only fetal swallowing activity, but also the 
development of adult sensitivities for thirst, A V P secretion and AVP responsiveness. ${ }^{67,68,78} \mathrm{~A} n$ animal study demonstrated that extracellular dehydration during pregnancy (commonly observed during pregnancy after vomiting or diarrhea) can enhance the natriophilic propensity in offspring and suggested that vomiting during pregnancy may contribute to the epidemiological factors of hypertension. ${ }^{78} \mathrm{~F}$ urthermore, mothers consuming excessive amounts of salt and water during pregnancy increase salt preference in adult offspring. ${ }^{79}$ Similar to dipsogenic mechanisms, peripheral and central fetal orexic mechanism also develop during intrauterine life. Prenatal ingestive behavior is manifested as swallowing and intake of amniotic fluid. By swallowing amniotic fluid, the fetus explores a wide variety of tastes even before birth. By the 7th week of gestation, taste buds develop in human embryos. ${ }^{80}$ Fetal taste bud cells are spread over a wider surface than in the neonate or the adult. ${ }^{81}$ It has been shown that sweet taste, such as that of a low-concentration sucrose solution, stimulates swallowing in the human fetus, whereas the incidence of swallowing movements decreases following the injection of Lipiodol-a bitter extract of poppy seeds used as a contrast- into the amniotic fluid. ${ }^{81}$ Sweet taste is already in utero the favorite taste. It has been found that although oral sucrose significantly stimulates near term ovine fetal ingestive behavior, sweet taste adaptation or habituation does not occur, in contrast to that observed in adult animals and humans. A bsence of taste adaptation in the fetus/newborn may facilitate increased neonatal food intake and accelerated growth. ${ }^{82}$ Increased or decreased glucose level in the serum does not affect the swallowing activity. ${ }^{81}$ The main feeding regulatory factors, neuropeptide $Y$ (NPY) and leptin, are secreted in the human fetuses as early as at 16 to 18 weeks respectively. ${ }^{83-85} \mathrm{NPY}$ is the most potent known inducer of food intake and leptin is a satiety factor. In some animal experiments, increased fetal swallowing has been demonstrated upon central NPY administration. ${ }^{86}$ The role of leptin in regulating ingestive behavior is interesting because, as opposed to its function in adults, leptin does not suppress fetal ingestive behavior. ${ }^{68}$ Fetal swallowing was significantly increased following the injection of leptin. ${ }^{87}$ Therefore, some investigators have postulated that the absence of leptin-inhibitory response potentiates feeding and facilitates weight gain in newborns, despite high body fat levels. ${ }^{88}$ Some findings suggest a possible role of leptin in the development of the fetal gastrointestinal tract. ${ }^{89}$ A part from determined high leptin concentration in amniotic fluid and in the gastrointestinal mucosa at the time when the fetus starts swallowing an early presence of $\mathrm{Ob}-\mathrm{Rb}$ (functional receptor of leptin) has been found in mucosa. This suggests a possible role for leptin, exerted endoluminally and in a paracrine pathway, in the developmental process (growth and/or maturation) of the human digestive tract. ${ }^{89}$ A ccording to some other studies, the potential in utero imprinting of appetite and satiety mechanisms may affect infant, childhood and ultimately adult appetite 'set-points'. An adverse intrauterine environment, with altered fetal orexic factors, could change the normal set-points of appetitive behavior and potentially lead to programming of adulthood hyperphagia and obesity. ${ }^{68,88}$ In a recent paper, prenatal exposure to over or undernutrition, rapid growth in early infancy, an early adiposity rebound in childhood and early pubertal development have all been implicated in the development of obesity. ${ }^{90}$ Further investigations are needed to delineate precisely the relationship between the intrauterine environment and the development of the set-points of adult appetite and thirst.

It is important to note that the function of the fetal digestive system also begins at an early stage of pregnancy. W ater, electrolytes and other small molecules, such as glucose are absorbed through the small bowel. ${ }^{21} \mathrm{By}$ 13 weeks, the intestine starts to absorb glucose and water swallowed by the fetus. ${ }^{65}$ Salivary amylase activity was found in the amniotic fluid in the late first-trimester pregnancies. Enzyme activity breaking down peptone is present in the small intestine of 7 to 10 week old fetuses and rises slightly after the 14th week of gestation. Lipase was found in the stomachs of fetuses in the 4th month of gestation, its activity increased with subsequent development. In addition, the $\mathrm{pH}$ of the gastric fluid in newborns is usually neutral or slightly acidic and the acidity increases shortly after birth, within several hours. The first traces of gastric acidity appear in 4 months old fetuses. ${ }^{91}$ Generally, during the last 2 to 3 months, fetal gastrointestinal function approaches that of the normal neonate. However, if the infant is more than 2 months premature, the digestive and absorptive systems are almost always inadequate. The absorption of fat is so poor that the premature infant must have low-fat diet. ${ }^{19}$ Insufficient fat absorption can cause problem to newborns that were fed milk that contains more fat than breast milk, such as undiluted cow milk. ${ }^{81}$

\section{Fetal Respiratory System}

Fetal lungs begin to develop in the 4th week after fertilization. A this time, the respiratory diverticulum (lung bud) appears ventrally to the caudal portion of the foregut. Angiogenesis in the lungs begins at the 5th week after fertilization. From the 16 to 26th week of pregnancy, formation of early respiratory units occurs and pneumocytes types II appear. From 26th week until birth, thinning of the 


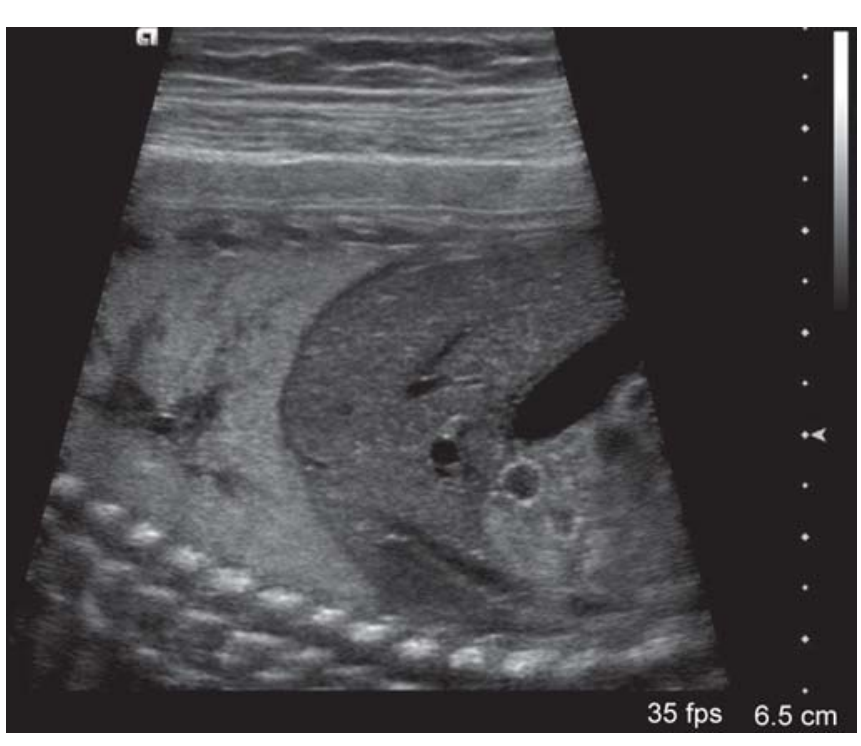

Fig. 15: Image of the fetus recorded by 2D sonography showing fetal lung and liver

respiratory membrane takes place, primitive alveoli dilate and establish close relationship with the capillaries. From 36th week onward, secondary alveolar septa, with rich capillary network, develop. Hence, respiratory surface enlarges. Further thinning of the respiratory membrane happens. ${ }^{46} \mathrm{M}$ ature neonate has $50 \%$ lower number of alveoli than an adult. Final number of alveoli is reached at 2 nd year of postnatal life. ${ }^{92}$ Normal fetal lung development requires the presence of lung liquid as well as fetal movements, like breathing. In the regulation of the lung liquid volume fetal breathing-like movements have a very important role. Other functions of breathing-like movements (Fig. 15) during intrauterine life are the development of respiratory muscles, widening of the alveolar spaces, maintenance of the lung liquid volume and lung organogenesis. ${ }^{93-95} \mathrm{~A}$ nimal investigation has shown that absence of respiratory movements (due to destruction of the brainstem nuclei above the phrenic nucleus) leads to hypoplasia of the lungs. ${ }^{96} \mathrm{~B}$ reathing-like movements appear at the 10th week ${ }^{97}$ Early in gestation, fetal breathing activity is variable and isolated event but the frequency and complexity of the breathing patterns change over the following weeks and months. Changes in breathing-like patterns are consequences of the maturation of the fetal lungs as well as the respiratory and sleep centers in the CNS. During the 38 to 39th week of gestation, the frequency of movements decrease to 41 respirations per minute and the movements become as regular as in the postnatal period..$^{98}$ A number of internal and external factors can influence fetal breathing-like movements during the second half of pregnancy. At 24 to 28 weeks, the fetal respiratory rate can rise as high as 44 inhale/exhale cycles per minute. ${ }^{99}$ This rate changes according to maternal carbon dioxide $\left(\mathrm{CO}_{2}\right)$ levels, strongly suggesting that respiratory center in the brainstem of the fetus al ready detects and responds to changes in $\mathrm{CO}_{2}$ levels in the blood. This respiratory response to $\mathrm{CO}_{2}$ is similar to that seen in newborns and adults. ${ }^{100}$ Furthermore, an increased number of fetal respiratory movements following the elevation of the glucose concentration in the maternal blood have been observed at the 34th week of gestation. ${ }^{101,102}$ Recent investigation has shown that intermittent maternal fasting is connected with a considerable alteration in the frequency and pattern of fetal breathing-like movements from the 30th week of gestation onward. ${ }^{103}$ Following premature rupture of membranes, ${ }^{104,105}$ during the 3 days prior to the initiation of labor, a decrease in fetal breathing-like has been recorded. ${ }^{106,107}$ However, similar maturation patterns in breathing and spontaneous fetal body movements were demonstrated among low-and high-risk fetuses threatening to deliver prematurely, which suggests normal functional development in the high-risk fetal group. ${ }^{108}$ Some studies have shown that maternal consumption of alcohol, methadone, as well as cigarette smoking decrease the incidence of breathing-like movements. ${ }^{109-111}$ On the contrary, aminophylline, conjugated estrogens and betamethasone are responsible for an increase in its frequency. ${ }^{112,113}$

One of the most important events in the lung development is production and secretion of surfactant. At the end of 6th month, alveolar cells pneumocytes type II appear and begin to secrete surfactant. These cells differ from pneumocytes type I by the presence of numerous surfactant containing granules, lamellar bodies. By adsorbing to the air-water interface of alveoli during the first breath, with the hydrophilic head-groups in the water and the hydrophobic tails facing toward the air, the main lipid component of surfactant, dipalmitoyl-phosphatidylcholine, reduces surface tension. In this way, surfactant prevents the closure of the alveoli, with each expiration. ${ }^{46}$ The composition of surfactant changes during fetal life. $M$ ature surfactant, rich with dipalmitoyl-phosphatidylcholine, is detectable after 35 weeks of gestation and indicates the functional maturity of fetal lungs. It is important to emphasize that the secretion of pulmonary surfactant in the lung liquid occurs only in the last weeks of fetal life. ${ }^{114}$ Besides phospholipids, surfactant contains proteins. Four types of surfactant-associated proteins have been described, SP-A, SP-B, SP-C and SP-D. They differ in structure, as well as in the function. SP-A and SP-D are hydrophilic molecules, they stimulate the secretion and removal of phospholipids and participate in maintaining of the homeostasis of surfactant. SP-B and SP-C are 
hydrophobic molecules as they enable the spreading of the phospholipid bilayer along the alveoli and improve the stability of surfactant. However, most important role of all proteins is the defense as they are participating in innate immune defense of the lung. In addition, they bind and react with many microorganisms, allergens and mitogens, and their receptors have been detected in alveolar macrophages. ${ }^{115} \mathrm{~V}$ arious hormones and inflammatory mediators affect the synthesis and secretion of surfactant. There are convincing data to support the use of antenatal corticosteroids in improving the respiratory outcome of newborn infants, especially those at greatest risk of devel oping respiratory failure. The current data suggest that this improvement may be due to enhanced expression of proteins and phospholipids of the surfactant system and enzymes of the antioxidant systems. N evertheless, caution is needed, as the scanty data that are available in animal models suggest that lung growth, especially the development of capillary network and secondary alveolar septa, as well as somatic growth may be adversely affected. ${ }^{116}$ The existence of receptors for triiodothyronine, thyroid hormone in the fetal lung, as well as certain studies conducted in animal models, suggest that this hormone also participates in the development of the fetal lung. Data have shown that thyroid hormones promote morphogenesis of lung histotypic structures but have a negative effect on surfactant synthesis. ${ }^{117,118}$ However, it seems that the role of prolactin, which increases in the serum of fetuses just before birth, is important for lung maturation. ${ }^{119}$ It is known that children of mothers who are heroin abusers have lower incidence of neonatal respiratory distress syndrome and heroin stimulates prolactin secretion. ${ }^{120}$ Studies conducted on experimental animals have shown that estrogen also stimulates the synthesis of surfactant in the fetal lungs too. ${ }^{121,122}$ Insulin and androgens play a role in inhibition of surfactant secretion. Higher incidence of neonatal respiratory distress in children of diabetic mother and in normal male neonates has been confirmed. Insulin and androgens inhibit synthesis of the surfactant. Chronic hyperglycemia with hyperinsulinemia have been connected with the delayed appearance of surfactant in the fetal lung tissue. ${ }^{123}$ The hypothesis that insulin achieves its inhibitory effect primarily by disruption of protein synthesis of surfactant was confirmed by studies on cell cultures of human pneumocytes type II. 124 However, it is interesting, that insulin, administered together with cortisol stimulates the synthesis of surfactant more than cortisol alone. ${ }^{124}$ Respiratory distress syndrome of new born is more common in male than in female children, possibly due to later start of surfactant production in male fetuses. This difference could be influenced by androgen effects, but definitely genetic factors have a certain role in it.125,126 Further, powerful modulators of lung maturation are inflammatory mediators, particularly interleukin 1, tumor necrosis factor- $\alpha$ and bacterial endotoxin. M aternal chorioamnionitis, in which the fetus is exposed to inflammatory agents, is a common cause of premature birth. However, these children, rarely suffer from respiratory distress syndrome. Still, although these cytokines enhance the maturation of the lungs and allow the survival of the child, their long-term effect is negative because they affect lung growth and development, especially vascularization. ${ }^{127}$ Therefore, in these children the respiratory surface is decreased. In addition, due to insufficient vascularization, vascular resistance in the lungs remains high after birth. This prevents the increase in flow through the lungs and leads to pulmonary arterial hypertension. ${ }^{128}$

A lthough the fetal lungs are functionally inactive during the entire period of intrauterine life, respiratory function becomes essential for survival of the infant immediately after birth. B reathing is initiated by sudden exposure to the exterior world and it is a consequence of slightly asphyxiated state due to the birth process and sensory impulses that originate from the suddenly cooled skin. If an infant does not begin to breathe immediately, progressive hypoxia and hypercapnia develop, and additionally stimulate the respiratory center. A t birth, the walls of alveoli are collapsed due to the viscid fluid that fills them. M ore than $25 \mathrm{~mm} \mathrm{Hg}$ of negative inspiratory pressure is required to oppose the effect of surface tension. First inspirations of the neonate are extremely powerful and capable of creating as much as $60 \mathrm{~mm} \mathrm{Hg}$ negative pressure in the intrapleural space. During first inspiration, about 40 milliliters of air enters the lungs. To deflate the lungs, considerable positive pressure is required because of viscous resistance offered by the fluid in the bronchioles. Expansion of the alveoli and increased concentration of oxygen in them stimulates the release of vasodilatator substances from the endothelium of capillaries. This, together with the mechanical stretching of the alveoli, leads to the dilatation of the lung capillaries and the resistance to blood flow in the pulmonary circulation decreases several fold. Development of a nearly normal compliance curve and normal postnatal breathing establishes within 40 minutes after birth. ${ }^{19}$

In addition to allowing gas exchange, increased blood flows through the lungs probably accelerate reabsorption of the lung liquid. A lthough the existence of lung liquid is necessary for the development of thelung, it must be quickly removed during delivery to allow normal breathing of the newborn. M ost of the lung liquid reabsorbs in the pulmonary circulation and only a small part of it removes through the 
upper airway during passage through the birth canal. Infusions of norepinephrine in concentrations, similar to those present at the delivery, prevent the lung liquid secretion. Hormones and factors that facilitate the removal of liquid from the lungs are arginine-vasopressin, catecholamine, prostaglandin- $E_{2}$, prolactin, surfactant, some growth factors and increase of the concentration of oxygen in the lungs, originating from the first breath. ${ }^{19}$

\section{Fetal Urinary System}

At the beginning of the fourth week, the intermediate mesoderm forms the nephrogenic cords. From the nephrogenic cords, three successive sets of excretory organs develop: The pronephros, the mesonephros and the metanephros. The first two, i.e. the pronephros and mesonephros, persist over a period of time and then regress, while the third, the metanephros, forms the definitive kidney. The permanent adult kidney, the metanephros, begins to develop early in the fifth week and is functional 2 to 3 weeks later. The ureteric bud develops as an outgrowth from the mesonephric duct. The ureteric bud forms the ureter, renal pelvis, calyces and collecting tubules. The nephrons are derived from the metanephric blastema. ${ }^{63}$ First nephrons appear in the kidney medulla, around 20 to 22 weeks of gestation, later they can be found in the periphery of the kidney. Formation of nephrons ends around the 35th week of gestation and further development occurs due to the growth of existing nephrons. ${ }^{129}$ At birth, the nephrons, approximately one million in each kidney, are formed but are still short. No new nephrons are formed after birth. During infancy, the nephrons complete their differentiation and increase in size until adulthood. ${ }^{63}$ Enlargement of the glomeruli, enlargement and elongation of the tubules, as well as enlargement of the vascular and connective tissue contribute to the growth of kidneys. ${ }^{130}$ Failure in the maturation of the primitive kidneys can lead to the abnormal development of the genital system, adrenal glands and lungs. ${ }^{129} \mathrm{~V}$ arious anomalies of the urinary tract can be caused by developmental disorders of pronephros and mesonephros. Developmental anomalies of the urinary tract account for about $40 \%$ of all anomalies. F requent occurrence of the urinary tract anomalies is due to complicated ontogenesis of this system. ${ }^{130}$ Recently, attention has been given to less noticeable but potentially very harmful consequences of impaired kidney development, such as a congenital nephron deficit. Since the lack of nephrons after birth is unrecoverable, numerous studies have been conducted to detect factors that in some way may impair the process of nephrogenesis. ${ }^{131}$ Studies conducted on the cell cultures of the fetal kidney showed that retinoids, metabolites of vitamin A, have a significant impact on the number of nephrons and that this effect is dose-dependent. Vitamin A deficiency in pregnant women is rare in developed countries but is more frequently observed in underdeveloped countries as a result of insufficient food intake. Even in a healthy population, concentrations of vitamin $A$ and retinoids in the plasma considerably vary. Habits that are most commonly associated with its low plasma values are cigarette smoking, alcoholism and unbal anced diets. ${ }^{131} \mathrm{U}$ nfortunately, lack of vitamin $\mathrm{A}$ is not the only factor that can lead to a nephron deficit. Experiments on animals have proved that fetal growth retardation, ${ }^{132}$ maternal hyperglycemia ${ }^{133}$ and some medications, such as gentamicin, ${ }^{134}$ cause a reduced number of nephrons, which cannot be fully compensated for after birth. If we remember that nephrogenesis in the humans ends before birth, we can assume that the harmful effects of these factors on the human fetus may be even more dangerous. Even a slight deficit of nephrons, often unrecognized after the birth, could be associated with diseases that occur later in the life, such as renal failure or hypertension. Therefore, more and more scientists believe that congenital nephron deficit could be a 'missing link' in understanding of the etiology of essential hypertension. ${ }^{131}$

For many years, data on fetal renal function have been insufficient and indirect. Investigations were carried out mainly in experimental animals and aborted fetuses. The insertion of a catheter into the fetal blood vessels and bladder allowed the testing under physiological conditions, and brought new insights about the function of the fetal kidneys, and the application of ultrasonic methods, enabled the noninvasive and easy way to study the physiology and pathophysiology of fetal urinary tract. Glomerular filtration rate in term-fetuses, measured by ultrasound and biochemical measurements, is 0.73 to $5.25 \mathrm{ml} / \mathrm{min}$, which amounts to $1 / 29$ to $1 / 4$ values in adults. A fter birth, during the first 4 days of life, glomerular filtration rate rapidly increases. ${ }^{134}$ It was found that the time of umbilical cord ligation influences on the value of gl omerular filtration rate. In the newborns in which umbilical cord ligation was performed relatively late after the birth, a circulating blood volume and glomerular filtration was 40 to $50 \%$ greater than in the newborns in which the umbilical cord ligation was done immediately after birth. ${ }^{129}$ Further, values of tubular reabsorption in fetal kidneys at term range between 55 and $97 \%$ of the adult values. ${ }^{135,136}$ Although histologically, kidney tubules seem well developed, at the time of delivery, the surface of transporting cells and the number of transporters is small. R eabsorption and excretory function are not completely developed. Immature cells 
tubules have low concentration of $\mathrm{Na}^{+} / \mathrm{K}^{+} \mathrm{ATP}$-ase, an enzyme that provides energy for active transport of sodium. ${ }^{137,138}$ Therefore, capacity of renal tubular cells for sodium transport is limited. Consequently, reabsorption of bicarbonates, glucose and phosphates is also limited. ${ }^{139-141}$ Due to low glucose threshold, tendency of excretion of glucose and consequently of the water and sodium is increased. Because of that in neonate, dehydration can develop more rapidly than in an adult. Further, it was found that term-fetus is not capable to respond on dehydration or hypertonic solution by creating concentrated urine, like adult. Sodium overload of the mature newborn and increase of plasmatic concentration of sodium can cause increase of the body mass due to generalized edema. If the newborn gets a cow's milk, which contains four times more sodium, protein and phosphate than mother's breast milk, signs of salt and fluid retention may occur. ${ }^{129}$ The fetus usually produces hypotonic urine and in case of dehydration, ability to concentrate urine does not exceed the limit of 600 to 700 $\mathrm{mOsm} / \mathrm{l}$. A ntidiuretic hormone (ADH), whose role is to preserve water in the body by concentrating the urine, the fetus begins to produce in the 11th week of pregnancy and its concentration in fetal blood is almost equal to the concentration in adults. Infusion of hypertonic $\mathrm{NaCl}$ solution, hypoxia or hypovolemia can increase concentration of ADH in fetal plasma. ${ }^{142,143}$ Therefore, we cannot talk about lack of ADH, as a cause of low osmolarity of fetal urine. However, it is possible to assume that the kidney is insensitive to $A D H$. The fetus cannot concentrate urine before appearing of specific water channels called aquaporin. They occur in human fetuses in the 12 to 15 th weeks of pregnancy but their expression in the fetus and newborn is much lower than in adults. ${ }^{142}$ Insensitivity of the fetal kidney to ADH could be explained by the slow emergence of these water channels. ${ }^{81}$ Further, hydrogen ion secretion in the fetus and newborn is sufficient to allow bicarbonate reabsorption and excretion of metabolic acids. Filtered phosphate and synthesized ammonia are in quantities sufficient for buffering excessive hydrogen ions. ${ }^{81}$ However, it is important to note that the fetal kidneys do not play a major role in the regulation of acid-base balance. Even in fetuses with renal agenesis, acid-base balance may be normal. ${ }^{129}$ In fetus, the acid-base balance is regulated by maternal lungs and kidneys. $\mathrm{CO}_{2}$ is quickly removed through the placenta into the mother' $s$ bl oodstream and then mother exhaled it. ${ }^{144} \mathrm{~L}$ arge amounts of $\mathrm{CO}_{2}$ can be effectively removed if the mother's respiration, the uteroplacental flow and the umbilical flow are normal. Somewhat, more slowly, metabolic acids are transferred through the placental barrier and they are excreted through the mother' s kidneys. ${ }^{145}$ Thus,

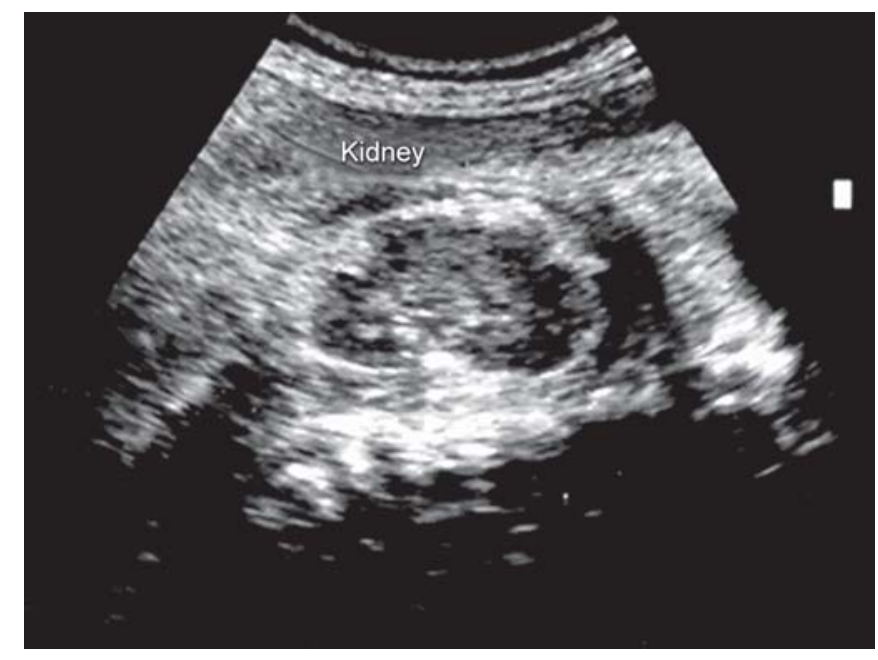

Fig. 16: 2D ultrasound image showing fetal kidney

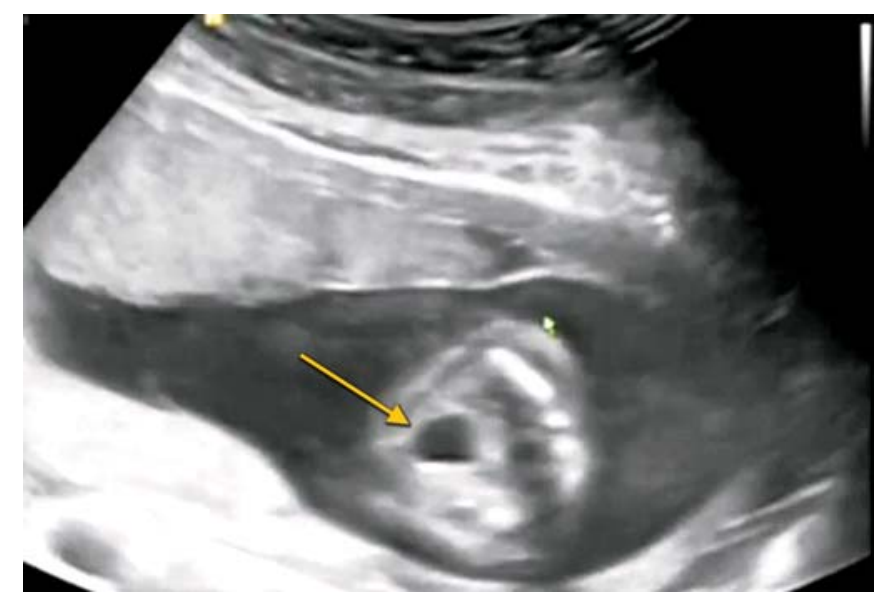

Fig. 17: 2D ultrasound image showing fetal bladder

regulation of fetal acid-base balance depends on many interrelated factors, which include state of the mother, placenta and the fetus.

Fetal kidneys (Fig. 16) excrete urine from the 3rd month of pregnancy. This can be confirmed by the existence of urine in the bladder of the fetus (Fig. 17). ${ }^{146,147}$ U rine extracted from the fetal kidney is hypotonic and that is not surprising because the main excretion function is performed by the placenta. Due to this fact, el ectrolyte composition of fetal urine is poor. ${ }^{146-148} \mathrm{The} \mathrm{pH}$ of fetal urine is about $6 .{ }^{149}$ By the midgestation, fetal urine becomes the main source of amniotic fluid and swallowing the main way of its removal. These two processes are essential elements in the production and regulation of amniotic fluid in the middle trimester. The term-fetus excretes in the amniotic fluid about 400 to $1200 \mathrm{ml}$ of urine daily. The fact that fetal urine is the main component of the amniotic fluid in the second half of pregnancy, allows us to determine the concentrations of electrolytes, creatinine, protein or glucose. Further, recording of their changes enables us to study the functional development and maturation of the fetal kidney during this 
period. ${ }^{81} \mathrm{~A}$ fter birth, the kidneys are still immature, more accurately, their functional capacity is limited. Due to this, disorders in the maintenance of homeostasis can easily develop. Exchange of fluid in the newborn is very large and the intensity of metabolism and acid production are higher than in the adult. Taking into account immaturity of the kidney, we can easily understand that in this period acidosis, dehydration and sometimes excessive hydration frequently develop. The disruption in the maintenance of homeostasis is more often if the child is born before term, in hypoxia or infection. Fetal kidneys and kidneys of newborn do not perform their functions poorly, indeed, they work impressively, but they need time to achieve the perfect harmony of their functions.

\section{Fetal Central Nervous System}

Development of the human CNS begins in the early embryonic period and proceeds through a sequence of very complicated processes long after delivery. CNS develops from the embryonic ectoderm. Cells that will become neurons and glial cells originate from the neural plate, which is located within the ectoderm and contains about 125,000 cells. The neural plate is formed in the early third week of pregnancy. Its lateral edges are gradually rising and approaching one another, forming first a concave area known as the neural groove and then the neural tube. Cranial and caudal opening of the neural tube are closing between the 25 and 27 th day of pregnancy. ${ }^{150}$ Failure of these openings to close contributes a major class of neural abnormalities. Further development is characterized by changes in size, shape and internal structure of the neural tube wall, which reflect the complex histogenetic processes. Since, some parts of the neural tube grow and develop at different speeds and intensities, it bends and changes its shape, forming the major subdivisions of the CNS. There are three subdivisions of the cranial part of the neural tube: prosencephalon, the mesencephalon, and the rhombencephalon. They will each eventually develop into distinct regions of the central nervous system: The forebrain (the cerebral cortex and basal ganglia), midbrain and posterior brain (the cerebellum, pons and medulla oblongata). From the caudal part of the neural tube develops the spinal cord. ${ }^{46}$

Early embryonic development is characterized by its immobilization. Prerequisite for fetal movements is the existence of interneuronal and neuromuscular connections. The earliest interneuronal connections- the synapses, can be detected in the spinal cord shortly before the onset of embryonic motility, at 6 to 7 weeks of gestation. ${ }^{151}$ Therefore, the neural activity leading to the first detectable movements is considered to originate from the spinal

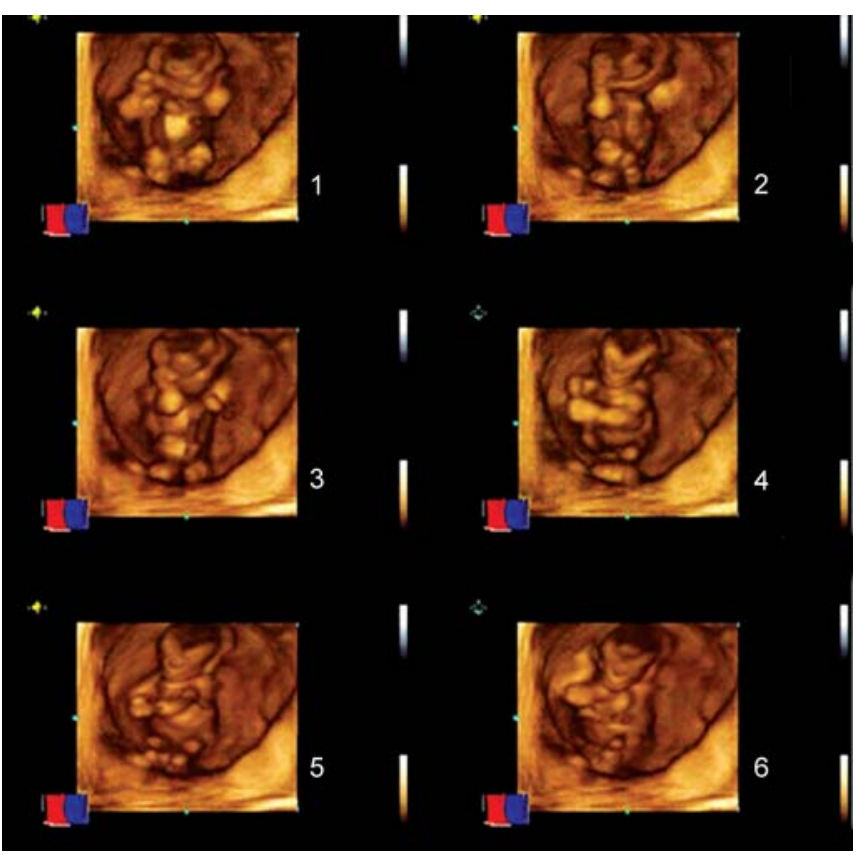

Fig. 18: A sequence of images of the fetus at 9 weeks of gestation recorded by $4 \mathrm{D}$ sonography showing general movements

motoneurons. ${ }^{152} \mathrm{~A}$ nother important prerequisite for the motility is the development and innervation of muscular fibers. It is well known that primitive muscle fibers (myotubes) are able to contract as soon as they are innervated by motor neurons. ${ }^{153} \mathrm{~B}$ etween 6 and 8 weeks of gestation, musclefibers haveformed by fusion of myoblasts, efferent and afferent neuromuscular connections have developed, and spontaneous neural activity causing motility can begin. The first spontaneous embryonic movements are gross body movements and they can be observed at the 7 to 7.5th weeks of gestation. They consist of slow flexion and extension of the fetal trunk, accompanied by the passive displacement of arms and legs. ${ }^{154}$ These, so called, 'vermicular' movements appear in irregular sequences. ${ }^{155}$ Simultaneously, with the onset of spontaneous movements, at the 7.5th week of gestation, the earliest motor reflex activity can be observed, indicating the existence of the first afferent-efferent circuits in the spinal cord. ${ }^{156}$ The first reflex movements are massive and indicate a limited number of synapses in a reflex pathway. General movements are the first complex, well-organized movement pattern, which involve head, trunk and limb movements. This pattern has been interpreted as the first sign of a supraspinal control on motor activity ${ }^{157,158}$ and can be recognized from 8 to 9 weeks of gestation onward (Fig. 18). ${ }^{158,159}$

The brainstem is fashioned around the 7th week of gestation ${ }^{157}$ and basic structures of the diencephalon and cerebral hemispheres are formed by the end of the 8th gestational week. ${ }^{159}$ The remarkable expansion of the cerebral hemispheres follows during the remainder of 
gestation. The development of synapses in the human cerebral cortex begins after the formation of the cortical plate, at the end of the 10th week of gestation. ${ }^{160,161}$ The brainstem consists of the medulla oblongata, pons and midbrain. It forms and matures in a caudal to rostral direction. That means that the fillogenetically older structures, such as the medulla oblongata, will form and mature earlier in the gestation. In addition to its many subnuclei, the medulla gives rise to a variety of descending spinal motor tracts which reflexively trigger limb and body movements. It also hosts the five cranial nerves (V III-XII), which exert tremendous influences on gross body movements, heart rate, respiration and the head turning. As the medulla matures in advance of more rostral structures of the brainstem, reflexive movements of the head, body, extremities, as well as breathing movements and al terations in heart rate, appear in advance of other functions.

The formation of pons begins almost simultaneously, but its maturation is more prolonged. The structures of the pons include the V and V III cranial nerves (vestibular nuclei of the nerve VIII) and the medial longitudinal fasciculus (MLF), pontine tegmentum, raphe nucleus and locus coeruleus, which exert widespread influences on arousal, including the sleep-wake cycles. Facial movements, which are al so controlled by V and VII cranial nerve, appear around 10 to 11 weeks. ${ }^{157}$ The brainstem gradually begins to take the control over fetal movements and behavioral patterns during the first trimester and continues its maturation in the second trimester, resulting in expansion and complexity of the behavioral repertoires. ${ }^{157}$

From 10 weeks onward, the number and frequency of fetal movements increase and the repertoire of movements begins to expand. Qualitative changes in general movements can be also observed. These movements, which are slow and limited amplitude during 8 to 9 weeks, become more forceful at 10 to 12 weeks. A fter the 12th week, they become more variable in speed and amplitude. ${ }^{162} \mathrm{U}$ sing fourdimensional (4D) sonography, Kurjak and collaborators have found that from 13 gestational weeks onward, a 'goal orientation' of hand movements appears and a target point can be recognized for each hand movement. ${ }^{163}$ A ccording to the spatial orientation, they classified the hand movements into several subtypes: H and to head, hand to mouth (Fig. 19), hand near mouth, hand to face, hand near face, hand to eye and hand to ear. Our recent longitudinal study, performed by $4 \mathrm{D}$ ultrasound in 100 fetuses from all trimesters of normal pregnancies, has shown increasing frequency of various movement patterns, such as general movements, isolated arm and leg movements, stretching, as well as head movements, during the first trimester. ${ }^{164} \mathrm{U}$ sing $4 \mathrm{D}$ sonography,

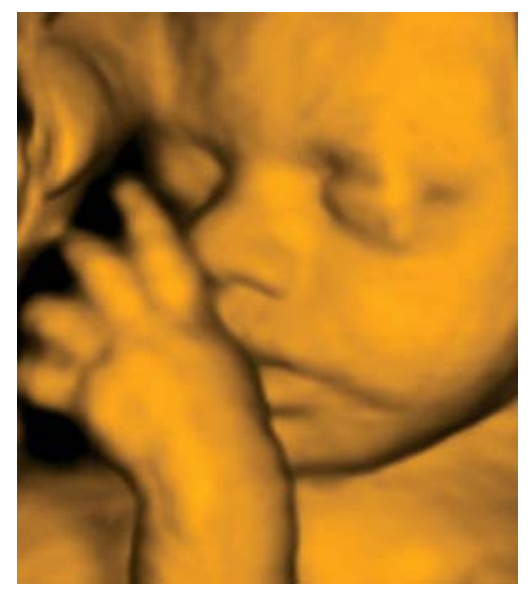

Fig. 19: Image of the fetus recorded by 3D/4D sonography showing hand-to-mouth movement
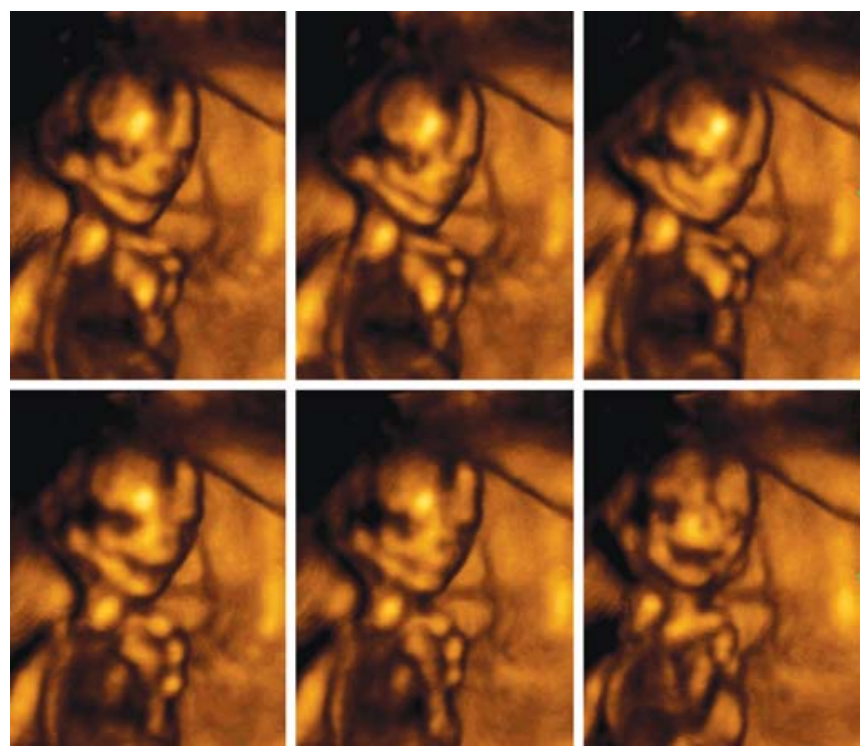

Fig. 20: A sequence of images recorded by $4 D$ sonography showing fetal mouth opening movements at 16 weeks of gestation

general movements were found to be the most frequent movement pattern between 9 and 14 weeks of gestation. ${ }^{165}$ From 14 to 19 weeks of gestation, fetuses are highly active and the longest period between movements last only 5 and 6 minutes. In the 15th week, 16 different types of movements can be observed. B esides the general body movements and isolated limb movements, retroflection, anteflection and rotation of the head can be easily seen. Moreover, facial movements such as mouthing (Fig. 20), yawning, hiccups, suckling and swallowing, can be added to the wide repertoire of fetal motor activity in this period. ${ }^{158}$ The earliest eye movements appear as sporadic movements with a limited frequency, at 16 to 18 weeks of gestation. ${ }^{166,167}$ The delayed onset of eye movements can be explained with later onset of midbrain maturation.

A lthough the midbrain begins to form at al most the same time as the pons, its maturation does not even begin until the 
second trimester. It consists of the dopamine producing substantia nigra, the inferiorauditory and superiorvisual colliculus, and cranial nerves III and IV , which, together with MLF and cranial nerve VI, control eye movements. ${ }^{16,167}$

Fetal human brain has a number of transitory structures, which cannot be observed in the adult human brain. One of the very important zone in the developing cortex is the subplate zone, that is a site for transient synapses and neuronal interactions. The development of subplate zone, between the 15 and 17th week of gestation, is accompanied with an increase in the number of cortical synapses, which probably form the substrate for the earliest cortical electric activity at 19 weeks of gestation. ${ }^{168}$ Subplate zone can play a major role in the developmental plasticity following perinatal brain damage. ${ }^{169}$

The second half of pregnancy is characterized by organization of fetal movement patterns and increase in complexity of movements. The periods of fetal quiescence begin to increase and the rest-activity cycles become recognizable. Hardly any new movement pattern emerges in this period. The number of general body movements, which tends to increase from the 9th week onward, gradually declines during the last 10 weeks of the pregnancy. ${ }^{170-172}$ A lthough this decrease was first explained as a consequence of the decrease in amniotic fluid volume, it is now considered to be a result of cerebral maturation processes. A s the medulla oblongata matures, myelinates and stabilizes, these spontaneous movements are less easily triggered, and begin to be controlled by more stable intrinsic activities generated within the brainstem. ${ }^{157}$ It is very important to point out that general movements are characterized by large variation and complexity in the third trimester. ${ }^{173}$ Revolutionary improvement in the study of fetal facial movements came with the development of $3 D$ and $4 D$ sonography. Our results confirmed the potential of $3 D / 4 D$ sonography for the investigation of structural and functional development of the fetal face. ${ }^{174}$ The application of $4 \mathrm{D}$ sonography in the examination of fetal facial movements has revealed the existence of a full range of facial expressions, including smiling, crying and eyelid movements, ${ }^{164,175}$ similar to emotional expressions in adults, in the 2nd and 3rd trimesters. Other facial movements, such as yawning, suckling, swallowing and jaw opening can al so be observed in this period by $4 \mathrm{D}$ ultrasound. Recent study demonstrated that the most frequent facial movement patterns in the 2nd trimester were isolated eye blinking, grimacing, suckling and swallowing, whereas mouthing, yawning, tongue expulsion and smiling could be seen less frequently. Mouthing was the most frequent facial movement during early third trimester ${ }^{176}$ (Figs 21A and B).

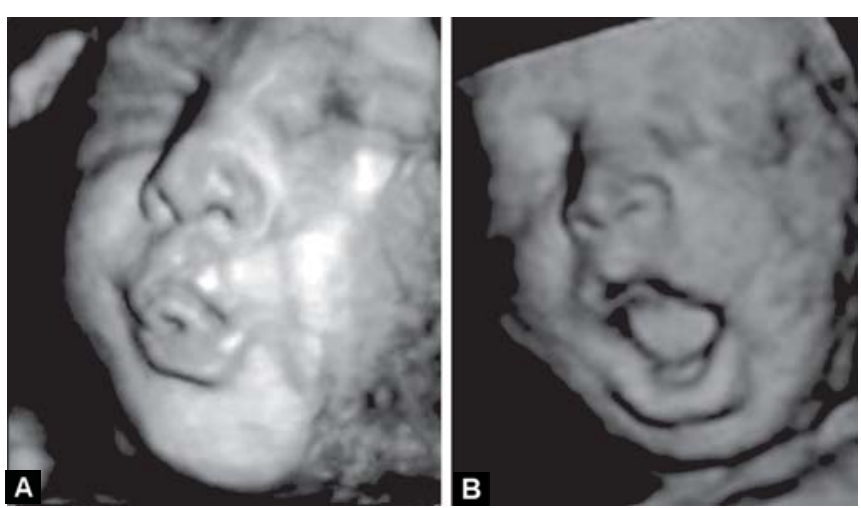

Figs 21A and B: Images of the fetus in the 3rd trimester recorded by $3 \mathrm{D} / 4 \mathrm{D}$ sonography, exhibiting mouthing movements
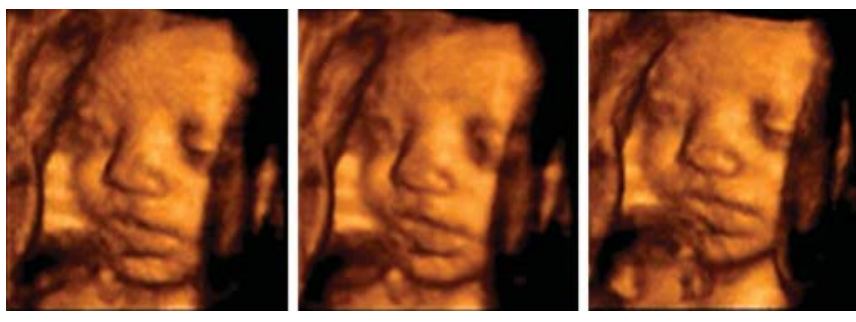

Fig. 22: A sequence of images of the fetus in the 3rd trimester recorded by $4 \mathrm{D}$ sonography showing eye blinking

Our longitudinal analysis of the frequencies of different facial movements in the 2 nd and 3rd trimester revealed some interesting results. Contrary to the declining trend of head movement and hand movement patterns from the beginning of the second trimester to the end of the third trimester, a constant increase in the frequencies of almost all facial movement patterns was observed during the 2 nd trimester. $\checkmark$ arious types of facial expression patterns displayed a peak frequency at the end of 2 nd trimester, except eye blinking pattern (Fig. 22), which displayed a peak frequency at 28 weeks of gestation. During the remainder of pregnancy, decreasing or stagnant incidence of facial expression patterns was noted. ${ }^{164} \mathrm{O}$ bviously, this devel opmental trend provides yet another example of the maturation of the medulla oblongata, pons and midbrain, or perhaps even the establishment of control of more cranial structures. The facts that even in the embryonic period same inductive forces that cause the growth and reshaping of the neural tube influence the development of facial structures and that many genetic disorders affecting the CNS are also characterized by dysmorphology and dysfunction of facial structures, emphasize the importance of structural and functional evaluation of the fetal face. ${ }^{159,177}$ O ur recent study has demonstrated that there were no movements observed in fetal life that were not present in neonatal life. Furthermore, prenatal- neonatal continuity exists even in subtle, fine movements such as facial mimics. ${ }^{178}$ 
In addition to morphological studies of the development of the central nervous system and studies about fetal behavior that provide insight into the functional development of central nervous system of fetuses, attention of researchers attracts the development of the fetal senses. For a long time, experts from different fields of science debate about whether the fetus feels pain. In humans, it is possible to distinguish several different reactions to pain. The simplestis reflex motor reaction, removal of stimulated body parts from painful stimuli. Next unconscious reaction involves the secretion of the so-called stress hormonescortisol and catecholamines. The most complex reaction is conscious perception of pain and emotional reaction to it. We can claim with certainty that the first two are already present in the fetal period. The earliest reactions to painful stimuli are motor reflexes, resembling withdrawal reflexes. They appear early in gestation. Reflex threshold is remarkably low and various kinds of stimuli may induce very holistic and unspecific reactions. It is important to emphasize that these reactions are completely reflexive, directed by the spinal cord, and higher perception or processing of painful sensation does not exist at this stage. ${ }^{179}$ Further, as early as 16 to 18 weeks of gestation, fetal cerebral blood flow increases during invasive procedures. ${ }^{180,181} \mathrm{~T}$ his increase of blood flow toward the brain may be mediated by the sympathetic system or by other undetermined mechanisms. ${ }^{181} \mathrm{~W}$ ith regard to the autonomic and endocrine responses to pain, an elevation of noradrenaline, cortisol and beta-endorphin plasma levels, in response to needle pricking of the innervated hepatic vein for intrauterine transfusion, was registered in a 23-w eek-old fetus. Pricking of the noninnervated placental cord insertion for the same purpose had no effect. ${ }^{182,183}$ Obviously, painful stimuli trigger a wide spectrum of reactions, such as activation of the hypothalamo-hypophysial axis or autonomic nervous system, without reaching the cortex. It has been suggested that neither motor reflexes nor hormonal stress responses to invasive procedures prove the existence of fetal pain. ${ }^{184}$ It is unknown whether and when the fetus begins consciously to feel pain. Functional thalamocortical connections are required for fetal awareness of noxious stimuli. Thalamocortical path is formed between 22 and 26 weeks and after this period, the fetus is probably capable of consciously perceiving painful stimuli. Evidence for conscious pain perception during intrauterine life is indirect, but evidence for the subconscious incorporation of fetal pain into neurological development and plasticity is incontrovertible. ${ }^{185}$ Despite the great interest in conscious experience and memory of pain, unconscious reactions like the secretion of stress hormones and their far-reaching detrimental effect, are probably more dangerous for the development of fetus than terrifying memories.

Reflex arcs involving the brainstem, such as vestibular, auditory and olfactory, mature early in fetal life. V estibular nerve cells mature earlier than neurons of the lateral and inferior vestibular nuclei, which begin to function during the 9th week of pregnancy. It is believed that vestibular stimulation has a role in the emerging fetal movements. Nearly weightless state of the fetus in the uterus provides a particularly convenient medium for the vestibular reflexes. According to electrophysiological examinations of evoked potentials in prematurely delivered heal thy infants, cochlear function develops between 22 and 25 weeks of gestation and its maturation continues during the first 6 months after delivery. ${ }^{186-188} \mathrm{H}$ owever, fluid in the fetal ear as well as the immaturity of the cochlea, complicate the sound transmission, so that only strong acoustic stimuli can be registered by the fetus. ${ }^{157}$ Due to this reason and because of the immaturity of the cochlea, a very strong stimuli is needed for fetus to notice it. $M$ aternal heartbeats and motility of gastrointestinal tract during digestion appear to generate 60 to 90 decibels of sound in utero, which is comparable to noise of the busiest street. ${ }^{189}$ During the last weeks of pregnancy, from the 36th gestational week onward, the fetus reacts to extremely loud sounds and even the mother's voice with reflex movements of the body, by turning his head, and increased heart rate. M ore fascinating is the notion that a fetus at this age not only hears sounds but also can discriminate between different sounds. This finding is explained by the tonotopic organization of the cochlear nuclei and by the maturation of the brainstem during the last weeks of pregnancy. It was noted that the devel opment of the auditory system can be disrupted by the influence of adverse factors (cigarette consumption) and also in some pathological conditions (intrauterine growth retardation, maternal hypertension). ${ }^{190-192}$ It is important to mention al so that development of the auditory system affects the subsequent learning of speech and language acquisition.

A nimal experiments have indicated that the intrauterine environment is not completely deprived of light. A lthough the developing fetus cannot distinguish objects clearly, the intensity of light is equal to the splendor that occurs through the cheek when mouth is highlighted by the powerful batteries. Furthermore, according to some experimental results, the development of visual and auditory organs could not be possible without any light or auditory stimulation. ${ }^{193,194}$ The structural development of sensory pathways is a prerequisite for functional development, but the final organization of the brain circuitries depends mainly on guidance from external inputs. ${ }^{169} \mathrm{~A}$ histological study 
of the human visual pathway has shown that thalamic projections reach the visual cortex between 23 and 27 weeks of gestation. ${ }^{195}$ The primary visual cortex can be clearly delineated in the occipital lobe by immunohistochemical staining even before the 25th week. In this cortical area, synaptogenesis persists between 24 weeks of gestation and 8 months after delivery, ${ }^{193}$ while myelination of the optical tract begins at 32 weeks of gestation. ${ }^{194}$ Cortical visual evoked potentials indicate the development and maturation of the primary visual cortex. $M$ aturation of the visual cortex is characterized by the appearance of surface-positive evoked potentials, which occurs between the 36 and 40th weeks. ${ }^{169} \mathrm{~N}$ ew data have shown that the amplitude of visual evoked responses can be used in the assessment of fetal and neonatal habituation to light stimuli. ${ }^{196} \mathrm{Flash}$ stimuli over the maternal abdomen can cause the visual evoked brain activity in the human fetus, recorded by magnetoencephal ography. The latency of the fetal response falls with increasing gestational age and begins to approach the adult latency near term. ${ }^{197}$ Recent experimental findings have demonstrated the importance of fetal eye motility in retinal (neuronal) cell differentiation, as well as eye functional maturation. ${ }^{198}$

Fetal life in utero is organized in cyclical patterns. From the midgestation onward, periods of activity begin to al ternate with the periods of rest. B etw een 30 and 38 weeks of pregnancy the difference betw een quiet and paradoxical, 'active' sleep can be seen. In advanced pregnancy, the fetus usually sleeps at the same time as the mother. In fetal animals, simultaneous measurements of fetal electrocortical activity, eye and body movements have shown that deep sleep, characterized by high-voltage waves and decreased fetal activity, occurred during $54 \%$ of a day. The total length of the REM sleep period, characterized by low-voltage waves and rapid eye movements, lasted $40 \%$ of a day. The wakeful state ( $6 \%$ of a day) is characterized by low-voltage waves. ${ }^{199}$ In human premature new borns, born 4 weeks prior to term, 60 to $65 \%$ of the total sleeping period is REM sleeping, whereas in term-newborns, the REM sleeping period includes $50 \%$ of the total 16 hours of sleep ${ }^{200}$ D uring delivery, fetal EEG shows waves characteristic for quiet sleep, active sleep and wakeful-ness of the newborn. ${ }^{201}$ It is thought that REM sleep plays a role in the development of the nervous system, similar as physical activity helps to develop muscles. REM sleep is probably caused by intense activity of neural circuits and thus participates in the development of the central nervous system. ${ }^{202}$

The human brain is intricately designed to execute cognitive functions, such as perception, attention, memory and learning. Psychobiologic investigations inspired the hypothesis that the acoustically rich environment in the uterus contributes to fetal learning. ${ }^{203}$ The intrauterine origin of learning and memory processes has been investigated extensively employing habituation methods, classical conditioning or exposure learning to assess fetal learning.

It was also found that the fetus has the ability to remember tastes to which it was exposed during the intrauterine period. Flavors from the mother's diet during pregnancy are transmitted to amniotic fluid and are swallowed by the fetus. Consequently, the type of food eaten by the mother during pregnancy is experienced by the infants before their first exposure to solid food. For instance, garlic ingestion by pregnant women significantly alters the odor of their amniotic fluid, barely 45 minutes after ingestion. ${ }^{204}$ Prenatal experience of taste greatly affects the newborn child. It prepares it for the taste of the mother's milk, whose taste also depends on the mother's diet. Prenatal and early postnatal exposure to a flavor enhances the infant's enjoyment of that flavor in solid foods during weaning. ${ }^{205}$ A study has shown that the infants who have been exposed to the flavor of carrots in either amniotic fluid or breast milk behaved differently in response to that flavor in food than did the nonexposed control infants. Specifically, previously exposed infants exhibited fewer negative facial expressions while being fed the carrot-flavored cereal compared to the plain cereal, whereas control infants whose mothers drank water during pregnancy and lactation exhibited no such difference. ${ }^{205}$ A ccording to recent data, the neonate strongly reacts to fragrant signals of mother's breasts. ${ }^{206,207}$ In the close proximity of mother's breasts, in the first minutes after birth, the new born spontaneously turns toward the breast and starts making the movement of sucking even before coming in the direct contact with the breast. ${ }^{208}$ In the first days of life, it demonstrates a similar reaction to its own amniotic fluid. ${ }^{209}$ To some extent, the chemical profile of breast secretions overlaps with that of amniotic fluid. Therefore, early postnatal attraction to odors associated with the nipple/areola may reflect prenatal exposure and familiarization. ${ }^{210}$

The development of human brain is not completed at the time of delivery. Only subcortical formations and primary cortical areas are well developed in a newborn. A ssociative cortex, barely visible in a newborn, is scantily developed in a 6 months old infant. Postnatal formation of synapses in associative cortical areas, which intensifies between the 8th month and the 2 nd year of life, precedes the onset of first cognitive functions, such as speech. Following the 2nd year of life, many redundant synapses are eliminated. Elimination of synapses begins very rapidly and continues slowly until puberty, when the same number of synapses as seen in adults is reached. ${ }^{211}$ 


\section{Fetal Stress}

A large number of environmental factors can trigger the fetal stress response. For instance, maternal undernutrition or placental insufficiency can alter the intrauterine environment, causing fetal stress. ${ }^{212}$ Painful stimuli al so lead to the fetal stress response. ${ }^{213}$ Even severe maternal emotional stress or stressful life events, according to some investigations, may influence the fetal environment. ${ }^{214-216}$ The primary role of stress is the protection of organism but fetal exposure to stress may affect neurodevelopment, as well as the development of many other organ systems and have lifelong consequences. M any adaptive changes induced by fetal stress increase the chance of fetal survival by creating a short-term protection. However, these changes can leave profound alterations in the structure and functions of the organism. ${ }^{212}$ It is a known fact that fetal cardiovascular adaptation to hypoxia is manifested by the redistribution of blood flow primarily toward the fetal brain. However, our latest investigations have shown that severe brain damage can develop despite the fetal blood flow redistribution and increased brain perfusion, even earlier than it was previously thought. ${ }^{217}$ The neuroendocrine stress axis includes the production of the corticotropin releasing hormone $(\mathrm{CRH})$, adrenocorticotropic hormone $(\mathrm{ACTH})$ and cortisol. Fetal $\mathrm{CRH}$ has been shown to influence the timing of birth. These findings have pointed to an active role of the fetus in the initiation of parturition. ${ }^{81}$ Furthermore, ACTH impairs motor coordination and muscle tonicity, reduces attention span and increases irritability. ${ }^{212}$ Recently, epidemiological and experimental investigations have shown that chronic exposure to high levels of cortisol during intrauterine life, occurring either as a result of its exogenous application or the fetal stress, has a very adverse effect in the long run. Unfortunately, it has been recently established that cortisol, which accelerates lung and brain maturation and enables survival of premature infants, may have an adverse effect on growth of the lungs, development of the secondary alveolar septa and even on the growth of the whole organism. ${ }^{218} \mathrm{~A}$ ccelerated maturation of the brain is also associated with the structural as well as behavioral changes. Stress induces structural changes of the hippocampus ${ }^{219-222}$ that are associated with memory impairment and learning disabilities. Behavioral changes associated with accelerated maturation of the brain include hyperalertness and impaired fetal responsiveness to novel stimuli. ${ }^{223} \mathrm{R}$ etrospective studies on children whose mothers experienced severe psychological stress or adverse life events during their pregnancy have suggested long-term neurodevelopment effects on the infant. ${ }^{224-227}$ Such children exhibited symptoms of attention deficit hyperactivity disorder, sleep disorders, unsociable and inconsiderate behavior, as well as psychiatric disorders, including schizophrenic episodes, depressive and neurotic symptoms, drug abuse and anxiety. ${ }^{228}$ Increased maternal stress during pregnancy seems to influence infant temperament and cognitive functions. ${ }^{229,230} \mathrm{M}$ oreover, stressful maternal life events measured during the first part of pregnancy negatively affected the child's attention/concentration index measured at the age of six. ${ }^{231}$ The adverse health effects of stress may also include an increased risk of certain birth defects (cleft palate, cleft lip with or without cleft palate, $d$-transposition of the great arteries and tetralogy of Fallot). ${ }^{214}$ Chronic high glucocorticoid exposure in utero is associated with adult hypertension and according to some data with coronary disease. Impaired glucose tolerance has also been noticed. ${ }^{232-234} \mathrm{~W}$ e can conclude that some of the most common diseases of the modern society may have their origins in prenatal life.

\section{CONCLUSION}

Fetal developmental potential is determined at the moment of conception by genetic inheritance. However, this development is modulated by environmental factors. Basic and clinical researches into fetal life present us with ever deeper understandings of important role that the environment plays in prenatal and postnatal life. It is important to recognize that both, the mother and the fetus, actively participate in the maintenance of the physiological intrauterine environment. U nfortunately, the fetus is not entirely protected from harmful influences of the external factors. By altering the intrauterine environment, these factors can have a long-term effect on fetal health. Finally, physiological fetal growth and development is the precondition for optimal child development.

\section{REFERENCES}

1. Stables D. Physiology in childbearing with anatomy and related biosciences. Edinburgh: Bailliere Tindall 1999:pp.73-148.

2. Wong $\mathrm{KHH}, \mathrm{A}$ dashi EY. Early conceptus growth and immunobiologic adaptations of pregnancy. In: Reece $E A$, Hobbins J C, Gant NF (Eds). Clinical obstetrics: The fetus and mother. Oxford: Blackwell Publishing L td; 2007:pp.3-19.

3. Huppertz B, K ingdom J CP. The placenta and fetal membranes. In: Edmonds KD (Ed). Dewhurst's textbook of obstetrics and gynaecology. Oxford: Blackwell Publishing Ltd; 2007: pp. 19-28.

4. http://www.centrus.com.br/DiplomaF M F/SeriesFM F/doppler/ capitulos-html/chapter_03.htm.

5. Kahn BF, Hobbins JC, Galan HL. Intrauterine Growth Restriction. In: Gibbs RS, K arlan BY, H aney A F, Nygaard (Eds). Danforth's Obstetrics and Gynecology. Philadel phia: Lippincott Williams and W ilkins; 2008: pp. 198-220. 
6. Baschat AA. Fetal growth restriction-from observation to intervention. J Perinat M ed 2010;38(3):239-46.

7. Harrington K, Goldfrad C, Carpenter RG, et al. Transvaginal uterine and umbilical artery D oppler examination of 12-16 weeks and the subsequent development of pre-eclampsia and intrauterine growth retardation. Ultrasound Obstet Gynecol 1997;9(2):94-100.

8. Rizzo G, A rduini D, Romanini C. U mbilical vein pulsations: A physiologic finding in early gestation. A m J Obstet Gynecol 1992; 167(3):675-77

9. Giles WB, Trudinger BJ, Baird PJ . Fetal umbilical artery flow velocity waveforms and placental resistance: Pathological correlation. Br J Obstet Gynaecol 1985;92(1):31-38.

10. Karsdorp VH, Dirks BK, van der Linden JC, et al. Placenta morphology and absent or reversed end diastolic flow velocities in the umbilical artery: A clinical and morphometrical study. Placenta 1996;17(7):393-99.

11. Baschat AA. Fetal responses to placental insufficiency: An update. BJ OG 2004;111(10):1031-41.

12. A rbeille $P, M$ aulik $D$, Fignon $A$, et al. A ssessment of the fetal $\mathrm{pO}_{2}$ changes by cerebral and umbilical $\mathrm{D}$ oppler on lamb fetuses during acute hypoxia. Ultrasound M ed Biol 1995;21(7): 861-70.

13. A rbeille $P$, Roncin $A, B$ erson $M$, et al. Exploration of the fetal cerebral blood flow by duplex Doppler linear array system in normal and pathological pregnancies. UItrasound Med Biol 1987;13(6):329-37.

14. Gramellini D, Folli MC, Raboni S, et al. Cerebral-umbilical Doppler ratio as predictor of adverse perinatal outcome. O bstet Gynecol 1992;79:416-20.

15. A rbeille P, M aulik D, Salihagić A, et al. Effect of long-term cocaine administration to pregnant ew es on fetal hemodynamics, oxygenation, and growth. Obstet Gynecol 1997;90(5):795-802.

16. Fignon A, Salihagic A, A koka S, et al. Twenty-day cerebral and umbilical Doppler monitoring on a growth retarded and hypoxic fetus. Eur J Obstet Gynecol Reprod Biol 1996;66(1): 83-86.

17. Laurini RN, A rbeille B, Gemberg C, et al. B rain damage and hypoxia in an ovine fetal chronic cocaine model. Eur J Obstet Gynecol Reprod Biol 1999;86(1):15-22.

18. Salihagic A, Georgescus M, Perrotin F, et al. Daily Doppler assessment of the fetal hemodynamic response to chronic hypoxia: A five case report. Prenat N eonat M ed 2000;5:35-41.

19. Guyton i Hall. M edicinska fiziologija. 11. Izdanje. Zagreb: M edicinska naklada; 2006: pp. 1042-52, 1027-41, 918-30.

20. Marieb EN. Human A natomy and Physiology (5th ed). San Francisco: Benjamin Cummings; 2000:pp. 1118-48.

21. Johnson MH, Everitt BI. Essential Reproduction (5th ed). Oxford: Blackwell Science; 2000:pp. 203-22.

22. Ross MG, Ervin MG, Novak D. Fetal Physiology. In: Gabbe SG, Niebyl JR, Simpson JL (Eds). Obstetrics normal and problem pregnancies. Philadelphia: Churchill Livingston Elsevier; 2007:pp. 26-54.

23. Handwerger S, Freemark M. The role of placental growth hormone and placental lactogen in the regulation of human fetal growth and development. J Pediatric Endocrinol M etabol 2000;13(4):343-56.

24. Lovinger RD, Kaplan SL, Grumbach M MJ. Congenital hypopituitarism associated with neonatal hypoglycemia and microphallus: Four cases secondary to hypothalamic hormone deficiencies. Pediatr 1975;87(6 Pt 2):1171-81.
25. Goodman H G, G rumbach M M , K apaln SL. G rowth and growth hormone. II. A comparison of isolated growth hormone deficiency and multiple pituitary hormone deficiencies in 35 patients with idiopathic hypopituitary dwarfism. N Eng J M ed 1968;278(2):57-68.

26. L emons J A, Ridenour R, Orsini EN. Congenital absence of the pancreas and intrauterine growth retardation. Pediatr 1979;64(2):255-57.

27. Lassare C, Hardouin S, Daffos F, et al. Serum insulin-like growth factors and insulin-like growth factors binding protein in the human fetus. Relationships with growth in normal subjects and in subjects with intrauterine growth retardation. Pediatr Res 1991;29(3):219-25.

28. A shton IK , Zapf J, Einschenk I, et al. Insul in-like growth factors IGF 1 and 2 in human fetal plasma and relationship to gestational age and fetal size during mid pregnancy. Acta Endocrinol 1985;110:558-63.

29. Basset NS, et al. The effect of maternal starvation on plasma insulin-like growth factor I concentration in the late gestation ovine fetus. Pediatr Res 1990;27:401-04.

30. Oliver $\mathrm{MH}$, et al. Glucose but not a mixed amino acid infusion regulates insulin like growth factor-I concentration in fetal sheep. Pediatr Res 1993;34:62-65.

31. Prada JA, Tsang RC. Biological mechanisms of environmentally induced causes of IUGR. Eur J Clin Nutr 1998;52 (Suppl 1):S21-27; discussion S27-28.

32. M irlesse $\mathrm{V}$, et al. Placental growth hormone levels in normal pregnancy and in pregnancies with intrauterine growth retardation. Pediatr Res 1993;34:439-42.

33. Gluckman PD, Grumbach M M, Kaplan SL. The human fetal hypothalamus and pituitary gland. U: Tulchinsky D, Ryan KJ, ur. M aternal-fetal endocrinology. Philadelphia: WB Saunders Company 1980; str 196.

34. Czeizel A E. Folic acid in the prevention of neural tube defects. J Pediatr Gastroenterol Nutr 1995;20(1):4-16.

35. Canfield M A, Collins JS, B otto LD, et al. Changes in the birth prevalence of selected birth defects after grain fortification with folic acid in the United States: Findings from a multi-state population-based study. Birth Defects Res A Clin M ol Teratol 2005;73(10):679-89.

36. Bower C, M iller M, Payne J, Serna P. Folate intake and the primary prevention of non-neural birth defects. A ust N Z J Public Health 2006;30(3):258-61.

37. Czeizel $A E$, Puhó $E$. M aternal use of nutritional supplements during the first month of pregnancy and decreased risk of Down's syndrome: Case-control study. Nutrition 2005;21(6):698-704.

38. Judge M P, Harel O, L ammi-K eefe C J . A docosahexaenoic acidfunctional food during pregnancy benefits infant visual acuity at four but not six months of age. Lipids 2007;42(2):117-22.

39. J udge MP, Harel $O, L$ ammi-K eefe CJ. M aternal consumption of a docosahexaenoic acid-containing functional food during pregnancy: B enefit for infant performance on problem-solving but not on recognition memory tasks at age 9 months. Am J Clin N utr 2007;85(6):1572-77.

40. Helland IB , Smith L, Saarem K, et al. M aternal supplementation with very-long-chain $n-3$ fatty acids during pregnancy and lactation augments children's IQ at 4 years of age. Pediatrics 2003;111(1):e39-44.

41. Hibbeln JR, Davis JM, Steer C, et al. M aternal seafood consumption in pregnancy and neurodevelopmental outcomes in childhood (A LSPAC study): A n observational cohort study. L ancet 2007;369(9561):578-85. 
42. Romieu I, Torrent M, Garcia-Esteban R, et al. M aternal fish intake during pregnancy and atopy and asthma in infancy. Clin Exp A llergy 2007;37(4):518-25.

43. Willers SM, Devereux G, Craig LC, et al. M aternal food consumption during pregnancy and asthma, respiratory and atopic symptoms in 5-year-old children. Thorax 2007;62(9): 773-79.

44. Kaiser L, Allen LH. Position of the A merican Dietetic Association: Nutrition and lifestyle for a healthy pregnancy outcome. J A m Diet A ssoc 2008;102(10):553-61.

45. Tucker Blackburn S, L ee L oper D. M aternal, fetal and neonatal physiology. A clinical perspective. Philadelphia-LondonToronto-M ontreal-Sydney-Tokyo: W B Saunders Company; 1992: pp. 228-47.

46. Sadler TW. Langmanova Medicinska embriologija. Zagreb:Školska knjiga; 1996: pp. 183-231, 232-41, 272-311, 374-415.

47. Sutton M J, Gill T, Plappert P. Functional anatomic devel opment in the fetal heart. In: Polin RA , Fox WW (Eds). Fetal and neonatal physiology. Philadel phia-L ondon-T oronto-M ontreal-SydneyTokyo: W B Saunders Company; 1992: pp. 598-607.

48. Sutton M J, Gill T, Plappert P. Functional anatomic development in the fetal heart. In: Polin RA , Fox W W (Eds). Fetal and neonatal physiology. Philadel phia-L ondon-T oronto-M ontreal-SydneyTokyo: W B Saunders Company; 1992: pp. 598-607.

49. Schats R, Jansen CAM, W ladimiroff JW. Embryonic heart activity: A ppearance and development in early human pregnancy. Br J Obstet Gynecol 1990,97(11):989-94.

50. M erchiers EH, Dhont M, De Sutter PA, et al. Predictive value of early embryonic cardiac activity for pregnancy outcome. A m J Obstet Gynecol 1991;165(1):11-14.

51. Berne RM , Levy M N. Fiziologija. 3. izd. Zagreb: M edicinska naklada; 1996: pp. 489-91,831-63, 879-907, 908-48.

52. Bancroft J. Researches in prenatal life. Oxford:B lackwell; 1946.

53. Bartelds B, van Bel F, Teitel DF, et al. Carotid, not aortic, chemoreceptors mediate the fetal cardiovascular response to acute hypoxemia in lambs. Pediatr Res 1993;34(1):51-55.

54. Jones CT, Robinson RO. Plasma catecholamines in fetal and adult sheep. J Physiol 1975;248:15-33.

55. Guissani DA, M c GrigleHHG, Spencer J A, etal. Effect of carotid denervation on plasma vasopressin level during acute hypoxia in late gestation sheep fetus. J Physiol 1994;477(1):81-87.

56. Green $L R, M c G$ arrigle $H H G$, B ennet $L$, et al. The effect of acute hypoxaemia on plasma angiotensin II in intact and carotid sinusdenervated fetal sheep. J Physiol 1994;470(P):81.

57. Richardson B, Korkola S, A ssano H, et al. Regional blood flow and the endocrine response to sustained hypoxaemia in the preterm ovine fetus. Ped Res 1996;40(2):337-43.

58. M yers DA, R obertshow $D, N$ athanielsz PW . Effect of bilateral splanchnic nerve section on adrenal function in the ovine fetus. Endocrinology 1990;127:2328-35.

59. Tucker Blackburn S, L ee L oper D. M aternal, fetal and neonatal physiology. A clinical perspective. Philadelphia-LondonToronto-M ontreal-Sydney-Tokyo: WB Saunders Company 1992:pp. 228-47.

60. Green $L R, M c$ Grigle H HG, B ennet $L$, et al. Effect of carotid sinus denervation on plasma endothelin-1 during acute isocapnic hypoxaemia im the late gestation ovine fetus (sažetak). J Soc Gynaecol Inv 1995;2(2):159.

61. Green $L R, B$ ennet $L$, Hanson $M A$. The role of nitric oxide synthesis in cardiovascular response to acute hypoxia in the late gestation sheep fetus. J Physiol 1996;497(Pt 1):271-77.
62. Heymann M A. Fetal cerebrovascular physiology. U : C reasy RK, Resnik R. M aternal-fetal medicine: principles and practice. 2 izd. Philadel phia-L ondon-T oronto-M ontreal-Sydney-Tokyo: WB Saunders Company; 1989: pp. 288-300.

63. Trivedi VN, Hay P, Hay JC. Normal embryonic and fetal development. In: ReeceEA , Hobbins J C, Gant NF (Eds). Clinical obstetrics: The fetus and mother. Oxford: B lackwell Publishing Ltd; 2007:19-35.

64. Grand RJ, W atkins J B, Torti FM . Development of the human gastrointestinal tract. A review. Gastroenterology 1976;70(5 PT. 1):790-810.

65. Cunningham FG, M acD onald PC, Gant NF, et al. Williams Obstetrics, 20th (ed). Stamford; A ppleton and Lange; 1997.

66. Diamant NE. Development of esophageal function. Am Rev Respir Dis 1985;131:S29-32.

67. Ross M G, Nijland J M . Development of ingestive behavior. A m J Physiol 1998;274:R879-93.

68. El-Haddad M A, D esai M, Gayle D, et al. In utero development of fetal thirst and appetite: Potential for programming. J SoC Gynecol Investig 2004;11(3):123-30.

69. Grassi R, Farina R, Floriani I, et al. A ssessment of fetal swallowing with gray-scale and color D oppler sonography. A m J Roentgenol 2005;185(5):1322-27.

70. Kurjak A, Andonotopo W, Hafner T, et al. N ormal standards for fetal neurobehavioral developments-Iongitudinal quantification by four-dimensional sonography. J Perinat M ed 2006; 34(1):56-65.

71. Ross MG, Kullama LK, O gundipe OA, et al. Ovine fetal swallowing response to intracerebroventricular hypertonic saline. J A ppl Physiol 1995;78(6):2267-71.

72. Ross M G, K ullama LK, O gundipe $O A$, et al. Central angiotensin Il stimulation of ovine fetal swallowing. J Appl Physiol $1994 ; 76(3): 1340-45$.

73. Davison J M, Gilmore EA, Dürr J. Altered osmotic thresholds for vasopressin secretion and thirst in human pregnancy. A $\mathrm{m}$ J Physiol 1984;246:105-09.

74. Ross M G, Sherman DJ, Schreyer $P$, et al. Fetal rehydration via amniotic fluid: Contribution of fetal swallowing. Pediat Res 1991;29(2):214-17.

75. Nijland MJ, Kullama LK, Ross M G. M aternal plasma hypoosmolality: Effects on spontaneous and stimulated ovine fetal swallowing. J M ater-Fetal M ed 1998;7(4):165-71.

76. El-Haddad MA, Chao CR, Ross M G. N-methyl-D-aspartate glutamate receptor mediates spontaneous and angiotensin IIstimulated ovine fetal swallowing. J Soc Gynecol Investig 2005;12(7):504-09.

77. Ross MG, Sherman DJ, Ervin MG, et al. Fetal swallowing: Response to systemic hypotension. A m J Physiol 1990;257: R130-34.

78. Nicolaidis S, Galaverna $\mathrm{O}$, M eltzer $\mathrm{CH}$. Extracellular dehydration during pregnancy increases salt appetite of offspring. A m J Physiol 1990;258(1 Pt 2):R281-83.

79. Vijande $M$, Brime JI, López-Sela $P$, et al. Increased salt preference in adult offspring raised by mother rats consuming excessive amounts of salt and water. Regul Pept 1996;66(12):105-08.

80. B radley RM, M istretta CM. The developing sense of taste. U: Olfaction and Taste V DA. Denton and JP Coghlan. N ew Y ork: A cademic; 1975:pp. 91-98.

81. Salihagić A, K urjak A, M edić M. Novije spoznaje o fiziologiji fetusa. In: Kurjak A, Đelemiš J (Eds). Ginekologija I perinatologija II. V araždin: Tonomir; 2003:112-52. 
82. El-Haddad M A, Jia Y, R oss M G. Persistent sucrose stimulation of ovine fetal ingestion: Lack of adaptation responses. J M atern Fetal N eonatal M ed 2005;18(2):123-27.

83. Kawamura K, Takebayashi S. The development of noradrenaline-, acetylcholinesterase-, neuropeptide $Y$ - and vasoactive intestinal polypeptide-containing nerves in human cerebral arteries. N eurosci L ett 1994;175(1-2):1-4.

84. Cetin I, M orpurgo PS, Radaelli T, et al. Fetal plasma leptin concentrations: Relationship with different intrauterine growth patterns from 19 weeks to term. Pediatr Res 2000;48(5): 646-51.

85. Jaquet $D, L$ eger J, L evy-M archal $C$, et al. O ntogeny of leptin in human fetuses and newborns: Effect of intrauterine growth retardation on serum leptin concentrations. J Clin Endocrinol M etab 1998;83(4):1243-46.

86. Roberts TJ, Caston-Balderrama A, Nijland M J, et al. Central neuropeptide $Y$ stimulates ingestive behavior and increases urine output in the ovine fetus. A m J Physiol Endocrinol M etab 2000;279:E 494-500.

87. Roberts TJ, Nijland MJ, Caston-Balderrama A, et al. Central leptin stimulates ingestive behavior and urine flow in the near term ovine fetus. H orm M etab Res 2001;33(3):144-50.

88. Ross M G, El-Haddad M, Desai $M$, et al. Unopposed orexic pathways in the developing fetus. Physiol Behav 2003;79(1): 79-88.

89. A paricio $T, K$ ermorgant $S, D$ armoul $D$, et al. L eptin and $O b-R b$ receptor isoform in the human digestive tract during fetal development. J Clin Endocrinol M etab 2005;90(11):6177-84.

90. A dair LS. Child and adolescent obesity: Epidemiology and developmental perspectives. Physiol B ehav 2008;94(1):8-16.

91. Cunningham FG, Gant NF, L eveno KJ, et al. Williams O bstetrics (21st ed). N ew Y ork: M cGraw-Hill; 2001.

92. Kotecha $S$. L ung growth: Implications for the newborn infant. A rch D is Child N eonatal Ed 2000;82(1):F69-74.

93. Dawes GS. B reathing before birth in animals and man. A $n$ essay in developmental medicine. N Engl J Med 1974;290(10): 557-59.

94. Olver RE, Strang L B. I on fluxes across the pulmonary epithelium and the secretion of lung liquid in the fetal lamb. J Physiol 1974;241(2):327-57

95. Jain L. A Iveolar fluid clearance in developing lungs and its role in neonatal transition. Clin Perinatol 1999;26(3):585-99.

96. Wigglesworth J S, D esai R. Effects on lung growth of cervical cord section in the rabbit fetus. Early Hum Dev 1979;3(1): 51-65.

97. de V ries JI, Visser GH, Prechtl HF. The emergence of fetal behavior. In: Qualitative aspects. Early Human Dev 1982;7(4):301-22.

98. Patrick J, Campbell K, C armichael L, etal. A definition of human fetal apnea and the distribution of fetal apneic intervals during the last 10 weeks of pregnancy. A m J Obstet Gynecol 1978;136(4):471-77.

99. Natale R, Nasello-Paterson C, Connors G. Patterns of fetal breathing activity in the human fetus at 24 to 28 weeks of gestation. A m J Obstet Gynecol 1988;158(2):317-21.

100. Connors G, Hunse $C$, Carmichael $L$, et al. Control of fetal breathing in the human fetus betw een 24 and 34 weeks gestation. A m J Obstet Gynecol 1989;160(4):932-38.

101. Natale R, Patrick J, Richardson B. Effects of maternal venous plasma glucose concentrations on fetal breathing movements. A m J Obstet Gynecol 1978;132(1):36-41.
102. Patrick J, Natale R, Richardson B. Patterns of human fetal breathing activity at 34 to 35 w eeks gestational age. A m J Obstet Gynecol 1978;132(5):507-13.

103. M irghani HM , W eerasinghe SD, Smith JR, et al. The effect of intermittent maternal fasting on human fetal breathing movements. Obstet Gynaecol 2004;24(6):635-37.

104. Roberts AB, Goldstein I, Romero R, et al. Fetal breathing movements after preterm premature rupture of membranes. A m J Obstet Gynecol 1991;164(3):821-25.

105. Kivikoski A, A mon E, Vaalamo PO, et al. Effect of thirdtrimester premature rupture of membranes on fetal breathing movements: A prospective case-control study. A m J Obstet Gynecol 1988;159(6):1474-77.

106. Richardson B, Natal e R, Patrick J. Human fetal breathing activity during induced labor at term. A m J Obstet Gynecol 1979;133(3):247-55

107. Besinger RE, Compton AA, Hayashi RH. The presence or absence of fetal breathing movements as a predictor of outcome in preterm labor. A m J Obstet Gynecol 1987;157(3):753-57.

108. Kisilevsky BS, Hains SM J, L ow JA. M aturation of body and breathing movements in 24-33 week-old fetuses threatening to deliver prematurely. Early Hum Dev 1999;55(1):25-38.

109. Fox HE, Steinbrecher M, Pessel D, et al. M aternal ethanol ingestion and occurrence of human breathing movements. A m J Obstet Gynecol 1978;132(4):354-61.

110. Richardson B, O'Grady J P, OIsen GD. Fetal breathing movements in response to carbon dioxide in patients on methadone maintenance. A m J Obstet Gynecol 1984;150(4): 400-04.

111. M anning FA, Wym Pugh E, Boddy K. Effect of cigarette smoking on fetal breathing movements in normal pregnancy. Br M ed J 1975;1(5957):552-58.

112. I shigava M , Y oneyama Y , Power GG et al. M aternal teophylline administration and breathing movements in late gestation human fetus. Obstet Gynecol 1996;88(6):973-78.

113. Cosmi EV, Cosmi E, La Torre R. The effect of fetal breathing movements on the uteroplacental circulation. Early Pregnancy 2001;5(1):51-52.

114. J obe A. D evelopment of the fetal lung. U : C reasy RK, Resnik R. M aternal- fetal medicine: Principles and practice. 2 izd Philadel phia-L ondon-T oronto-M ontreal-Sydney-T okyo: W B Saunders Company; 1989:pp. 288-300.

115. Haagsman HP, Demiel RV. Surfactant associated proteins: Functions and structural variations. Comp Biochem A M ol Integr Physiol 2001;129(1):91-108.

116. V yas JR, K otecha $S$. The effect of antenatal and postnatal corticosteroids on the preterm lung. Arch Dis Child Fetal Neonatal Ed 1997;77:F 147-50.

117. Hundertmark S, Ragosch V, Zimmermann B, et al. Effect of dexametasone, triiodothyronine and dimetyl-isopropylthyronine on the maturation of the fetal lung. J Perinat Med 1999;27(4):309-15.

118. Chan L, M iller TF, Y uxin J, et al. A ntenatal triiodothyronine improves neonatal pulmonary function in preterm lambs. J Soc Gynecol Investig 1998;5(3):122-26.

119. Debieve F, Beerlandt S, Hubinot $C$, et al. Gonadotropines, prolactin, inhibin $A$, inhibin $B$, and activin $A$ in human fetal serum from midpregnancy and term pregnancy. J Clin Endocrin M etab 1997;85(1):270-74.

120. Glass L, Rajegowda BK, Evans HE. A bsence of respiratory distress syndrome in premature infants of heroin-addicted mothers. Lancet 1971;2(7726):685-86. 
121. Thuresson-K lein A, M oawad A H, Hedqvust P. Estrogen stimulates formation of lamellar bodies in the rat fetal lung. A $m$ J Obstet Gynecol 1985;151(4):506-14.

122. A damson IY, B akowska , M c M illan E, et al. A ccelerated fetal lung maturation by estrogen is associated with an epithelialfibroblast interaction. In Vitro Cell Dev Biol 1990;26(8): 784-90.

123. Warburton D. Chronic hyperglycemia reduces surface active maternal flux in tracheal fluid of fetal lambs. J Clin Invest 1983;71(3):550-55.

124. Dekowski SA, Snyder J M. The combined effect of insulin and cortisol on surfactant protein mRNA levels. Pediatr Res 1995;38(4):513-21.

125. K lein J M, Niel sen HC. A ndrogen regulation of epidermal growth factor receptor binding activity during rabbit fetal devel opment. J Clin Invest 1993;91(2):425-31.

126. Hallman M, Glumoff $V$, Ramet M. Surfactant in respiratory distress syndrome and lung injury. Comp Biochem Physiol A Mol Integr Physiol 2001;(1):287-94.

127. Jobe $A H$, Ikegami $M$. A ntenatal infection/inflammation and postnatal lung maturation and injury. Resp Res 2001;2(1): 27-32.

128. M ardešic D i sur. Pedijatrija. 6. izd. Zagreb:Školska knjiga; 2000: pp. 303-94.

129. K leinmann LI. The kidney. In: Stave U (Ed). Perinatal physiology. New Y ork-London: Plenum Medical Book Company; 1978:pp. 589-616.

130. Çvorić $A$. Razvoj bubrega i bubrežnih funkcija. In: Koraè $D$. Pedijatrija. Beograd. Zagreb: M edicinska knjiga; 1983: pp. 441-43.

131. Gilbert $T$, M erlet-B énichou $C$. Retinoids and nephron mass control. Pediatr Nephrol 2000;14(12):1137-44.

132. M erlet-B enichou C, Gilbert M , M uffet-J oly M , et al. Intrauterine growth development leads to a permanent nephron deficit in the rat. Pediatr N ephrol 1994;8(2):175-80.

133. A mri K, Freund N, Vilar J, et al. Adverse effects of hyperglycemia on kidney development in rats: In vivo and in vitro studies. Diabetes 1999;48(11):2240-45.

134. Gilbert T Gaonach S, M oreau E, et al. D efect of nephrogenesis induced by gentamicin in rat metanephric organ culture. $L a b$ Invest 1994;70(5):656-66.

135. Kurjak A, K irkinen $P, L$ atin $V$, et al. U Itrasonic assessment of fetal kidney function in normal and complicated pregnancies. A m J Obstet Gynecol 1981;141(3):266-70.

136. W ladimiroff $J W$. Effect of furosemide on fetal urine production. B r J Obstet Gynaecol 1975;82(3):221-24.

137. A peria $A$, Larsson $L$, Zetterström R. Hormonal induction of $\mathrm{Na}^{+} / \mathrm{K}^{+}$A TPase in developing proximal tubular cells. A m J Physiol 1981;241(4): F356-60.

138. Schmidt U, Horster M . $\mathrm{Na}^{+}-\mathrm{K}^{+}$- activated ATPase: A ctivity maturation in rabbit nephron segments dissected in vitro. A m J Physiol 1977; 233: F55-61.

139. A rant $B S$ J r. Developmental patterns of renal function maturation compared in the human neonate. J Pediatr 1978;92(5):705-12.

140. Karlen J, Paeria A, Zetterström R. Renal excretion of calcium and phosphate in preterm and fullterm infants. J Pediatr 1985;106:814-19.

141. Schwartz GJ , Evan A P. Development of solute transport in rabbit proximal tubule. In: $\mathrm{HCO}_{3}{ }^{-}$and glucose absorption. A m J Physol 1983;245:F382-86.

142. Battaglia FC, M eschia IG. A n introduction to fetal physiology. Orlando: A cademic Press 1986: pp. 154-67, 184-85.
143. Devuyst 0, Burrow $C R$, Smith $B L$, et al. Expression of aquaporins -1 and -2 during nephrogenesis and in autosomal dominant poycystic kidney disease. A m J Physiol 1996;271(1 Pt 2):F169-83.

144. Boylan PC, Parisi VM. Fetal acido-base balance. In: Creasy RK, Resnik R (Eds). Maternal-fetal medicine: Principles and practice. Philadel phia-L ondon-Toronto-M ontreal-SydenyTokyo: WB Saunders Company; 1989: pp. 362-73.

145. Winkler CA, Kittelberger $A M$, W atkins RH. M aturation of carbonic anchidrase IV expression in rabbit kidney. A m J Physiol Renal Physiol 2001;280(5):F895-903.

146. M CCance RA, Widdowson $E M$. R enal function before birth. U: Widdowson EM. Studies in perinatal physiology. 1. izd. Bath:Pitman press; 1980: pp. 94-103.

147. M cGroy WW. Development of renal function in utero. Cambridge: Harvard University Press; 1972: pp. 51-78.

148. M CC ance RA, Y oung WF. The secretion of urine by newborn infants. U: W iddowson EM. Studies in perinatal physiology. 1. izd. Bath: Pitman press; 1980: pp. 45-50.

149. McCance RA, V on Fimck MA. The titratable acidity, $\mathrm{pH}$, ammonia and phosphates in the urine of very young infants. $U$ : Widdowson EM. Studies in perinatal physiology. 1. izd. Bath: Pitman press; 1980: pp. 81-88.

150. J udaš M , Kostović I. Temelji neuroznanosti. 1. izd. M D Zagreb 1997: pp. 24-31,622-42,353-60

151. Okado N, Kakimi S, K ojima T. Synaptogenesis in the cervical cord of the human embryo: Sequence of synapse formation in a spinal reflex pathway. J Comp Neurol 1979;184(3):491-518.

152. Okado N, Kojima T. Ontogeny of the central nervous system: N eurogenesis, fiber connection, synaptogenesis and myelination in the spinal cord. In: Prechtl HFR (Ed). Continuity of neural function from prenatal to postnatal life. Oxford: Blackwell Science; 1984: pp. 31-35.

153. $L$ andmesser $L T, M$ orris $D G$. The development of functional innervation in the hind limb of the chick embryo. J Physiol $1975 ; 249(2): 301-26$.

154. Prechtl HFR. U Itrasound studies of human fetal behaviour. Early Hum Dev 1985;12(2):91-98.

155. Ianniruberto A, Tajani E. Ultrasonographic study of fetal movements. Semin Perinatol 1981;4:175-81.

156. O kado N. O nset of synapse formation in the human spinal cord. J Comp Neurol 1981;201(2):211-19.

157. Joseph R. Fetal brain and cognitive development. Dev Rev 1999;20:81-98.

158. de V ries JIP, V isser GHA, Prechtl HFR. The emergence of fetal behavior. I. Qualitative aspects. Early Human Dev 1982;7(4):301-22.

159. Pomeroy SL, V olpe JJ. Development of the nervous system. In: Polin RA, Fox, WW (Eds): Fetal and neonatal physiology. Philadel phia: L ondon-Toronto-M ontreal-Sydney-Tokyo: W B Saunders Company; 1992:pp. 1491-509.

160. K ostović I, Judas M. Transient patterns of cortical lamination during prenatal life: Do they have implications for treatment? Neurosci Biobehav Rev 2007;31(8):1157-68.

161. M olliver M E, K ostovic I, V an der Loos H. The devel opment of synapses in cerebral cortex of the human fetus. Brain Res 1973;50(2):403-07.

162. Lüchinger $A B$, Hadders- $A$ lgra $M$, van $K$ an $C M$, et al. Fetal onset of general movements. Pediatr Res 2008;63(2):191-95.

163. K urjak $A$, A zumendi $G, V$ ecek $N$, et al. Fetal hand movements and facial expression in normal pregnancy studied by fourdimensional sonography. J Perinat M ed 2003;31(6):496-508. 
164. Kurjak A, A ndonotopo W, Hafner T, et al. N ormal standards for fetal neurobehavioral developments-Iongitudinal quantification by four-dimensional sonography. J Perinat M ed 2006;34(1):56-65.

165. Andonotopo W, Medic M, Salihagic-Kadic A, et al. The assessment of fetal behavior in early pregnancy: Comparison between 2D and 4D sonographic scanning. J Perinat Med 2005;33(5):406-14.

166. A woust J, Levi S. N eurological maturation of the human fetus. Ultrasound Med Biol 1983; Suppl 2:583-87.

167. Inoue M, K oyanagi T, Nakahara H. Functional development of human eye-movement in utero assessed quantitatively with realtime ultrasound. A m J Obstet Gynecol 1986;155(1):170-74.

168. Kostović I, Rakic P. Developmental history of the transient subplate zone in the visual and somatosensory cortex of the macaque monkey and human brain. J Comp Neurol 1990;274(3):441-70.

169. Kostović I, Judas M, Petanjek Z, et al. Ontogenesis of goaldirected behavior: A natomo-functional considerations. Int J Psychophysiol 1995;19(2):85-102.

170. D'Elia A, Pighetti M, Moccia G, et al. Spontaneous motor activity in normal fetus. Early Human Dev 2001;65(2):139-44.

171. Natale R, Nasello-Paterson C, Turlink R. Longitudinal measurements of fetal breathing, body movements, and heart rate accelerations, and decelerations at 24 and 32 weeks of gestation. A m J Obstet Gynecol 1985;151(2):256-63.

172. Eller DP, Stramm SL, Newman RB. The effect of maternal intravenous glucose administration on fetal activity. A m J Obstet Gynecol 1992;167(4 Pt 1):1071-74.

173. Haddres-A Igra M. Putative neural substrate of normal and abnormal general movements. Neurosci Biobehav Rev 2007;31(8):1181-90.

174. Kurjak A, A zumendi G, A ndonotopo W, et al. Three- and fourdimensional ultrasonography for the structural and functional evaluation of the fetal face. Am J Obstet Gynecol 2007; 196(1):16-28.

175. K ozuma S, B aba K, O kai T, et al. Dynamic observation of the fetal face by three-dimensional ultrasound. Ultrasound Obstet Gynecol 1999;13(4):283-84.

176. $\mathrm{Y}$ an $\mathrm{F}$, Dai SY, A kther $\mathrm{N}$, et al. Four-dimensional sonographic assessment of fetal facial expression early in the third trimester. Int J Gynaecol Obstet 2006;94(2):108-13.

177. M erz E, W eller C. 2D and 3D ultrasound in the evaluation of normal and abnormal fetal anatomy in the second and third trimesters in a level III center. Ultraschall Med 2005;26(1): 9-16.

178. Kurjak A, Stanojevic M, A ndonotopo W, et al. B ehavioral pattern continuity from prenatal to postnatal life: $A$ study by four-dimensional (4D) ultrasonography. J Perinat Med 2004;32(4):346-53.

179. V anhatalo S, van Nieuvenhuizen O. Fetal pain? Brain Dev 2000;22(3):145-50.

180. Teixeira J M, Glover V, Fisk NM . A cute cerebral redistribution in response to invasive procedures in the human fetus. A m J Obstet Gynecol 1999;181(4):1018-25.

181. Smith RP, Gitau R, G lover V, et al. Pain and stress in the human fetus. Eur J Obstet Gynecol Reprod Biol 2000;92(1):161-65.

182. Giannakoulopoulos X, Sepulveda W, Kourtis P, et al. Fetal plasma cortisol and beta endorphin response to intrauterine needling. Lancet 1994;344(8915):77-81.
183. Giannakoulopolous X, Teixeira J, Fisk N, et al. Human fetal and maternal noradernaline responses to invasive procedures. Pediatr Res 1999;45(4 Pt 1):494-99.

184. Lee SJ, Ralston HJ, Drey EA, et al. Fetal pain: A systematic multidisciplinary review of the evidence. JAMA 2005; 294(8):947-54.

185. L owery $C L, H$ ardman M $P, M$ anning $N$, et al. Neurodevelopmental changes of fetal pain. Semin Perinatol 2007;31(5): 275-82.

186. M orlet $\mathrm{T}$, Collet $\mathrm{L}$, Salle B, et al. Functional maturation of cochlear active mechanisms and of the medial olivocochlear system in humans. A cta O tolaryngol 1993;113(3):271-77.

187. M orlet T, Collet L, Duclaux R, et al. Spontaneous and evoked otoacustical emissions in preterm and full term neonates: Is there a clinical application? Int J Ped OtoRhinoLaryngol 1995; 33(3):207-11.

188. Leader $L R, B$ aille $P, M$ artin $B$, et al. The assessment and significance of habituation to a repeated stimulus by the human fetus. Early Human Dev 1982;7(3):211-19.

189. Liley A W. Fetus as a person. Speach held at the 8th meeting of the psychiatric societies of A ustralia and New Zealand. Fetal Therapy 1986;1:8-17.

190. Sun W, Hansen A, Zhang L, et al. N eonatal nicotine exposure impairs devel opment of auditory temporal processing. Hear R es 2008;245(1-2):58-64.

191. Kiefer I, Siegel E, Preissl H, et al. Delayed maturation of auditory-evoked responses in growth-restricted fetuses revealed by magnetoencephalographic recordings. A m J O bstet Gynecol 2008;199(5):503.e1-7.

192. L ee CT, B rown CA, H ains SM , et al. Fetal development: $V$ oice processing in normotensive and hypertensive pregnancies. Biol Res N urs 2007;8(4):272-82.

193. H uttenlocher PR, de Courten $\mathrm{CH}$. The development of synapses in striate cortex of man. Human N eurobiol 1987;6(1):1-9.

194. M agoon EH, R obb RM . Development of myelin in human optic nerve tract. A light and electron microscopic study. A rch Ophtalmol 1981;99(4):655-59.

195. K ostovic I, Rakic P. D evelopment of prestriate visual projections in the monkey and human fetal cerebrum revealed by transient cholinesterase staining. J Neurosci 1984;4(1):25-42.

196. Sheridan CJ, Preissl H, Siegel ER, et al. Neonatal and fetal response decrement of evoked responses: A MEG study. Clin Neurophysiol 2008;119(4):796-804.

197. Eswaran H, Wilson J, Preissl H, et al. M agnetoencephalographic recordings of visual evoked brain activity in the human fetus. L ancet 2002;360(9335):779-80.

198. K ablar B. Determination of retinal cell fates is affected in the absence of extraocular striated muscles. Dev Dyn 2000;226(3):478-90.

199. Ruckenbush Y, Gaujoux M , Eghbali B. Sleep cycles and kinesis in the fetal Iamb. Electroenceph Clin Neurophysiol 1977; 42(2):226-37.

200. K elly DD. Sleep and dreaming. In: K andell ER, Schwartz JH (Eds). Principles of neural science ( 2 nd ed). New Y orkA msterdam-Oxford: Elsevier Science Publishing; 1985:p. 651.

201. Rosen M G, Scibetta J J, Chik L, et al. A n approach to the study of brain damage: The principles of fetal FEEG. A m J Obstet Gynecol 1973;115:37-47.

202. Roffag HP, M uzio J N, Dement WC. Ontogenetic development of the human sleep-dream cycle. Science 1966;152(3722): 604-19. 
203. A brams RM, Gerhardt KJ. The acoustic environment and physiological responses of the fetus. J Perinatol 2000;20(8 Pt 2):S31-36.

204. M ennella J A, J ohnson A, B eauchamp GK. G arlic ingestion by pregnant women al ters the odor of amniotic fluid. Chem Senses 1995;20(2):207-09.

205. M ennella JA, Jagnow CP, B eauchamp GK. Prenatal and postnatal flavor learning by human infants. Pediatrics 2001;107(6):E 88.

206. Varendi $\mathrm{H}$, Porter $\mathrm{RH}, \mathrm{W}$ inberg $\mathrm{J}$. Does the newborn baby find the nipple by smell? Lancet 1994;334(8928):989-90.

207. Varendi $\mathrm{H}$, Porter $\mathrm{RH}$, Winberg J . Natural odour preference of new born change over time. A cta Pediatrica 1997;86:985-90.

208. Widstrom AM, Ransjö-A rvidson AB, Christensson K, et al. Gastric suction in heal thy newborn infant. Effects on circulation and developing feeding behavior. Acta Paediatr Scand 1987;76(4):556-72.

209. Varendi H, Porter RH, Winberg J. A ttractiveness of amniotic fluid odor: Evidence of prenatal olfactory learning? A cta Paediatr 1996;85(10):1223-27.

210. Porter RH, W inberg J. U nique salience of maternal breast odors for newborn infants. Neurosci Biobehav Rev 1999;23(3): 439-49.

211. Kostovic I. Prenatal development of nucleus basalis complex and related fiber system in man: A histochemical study. Neuroscience 1986;17(4):1047-77.

212. Salihagic Kadic $A, M$ edic $M, K$ urjak $A$. Recent advances in neurophysiology. In: Kurjak A, A zumendi $G(E d s)$. The fetus in three dimensions. London: Informa Healtcare; 2007: pp. 411-33.

213. A nand KJ. Clinical importance of pain and stress in preterm neonates. Biol Neonate 1998;73(1):1-9.

214. Carmichael SL, Shaw GM, Y ang W, et al. M aternal stressful life events and risks of birth defects. Epidemiology 2007; 18(3):356-61.

215. M onk C, Fifer W P, M yers M M , et al. M aternal stress responses and anxiety during pregnancy: effects on fetal heart rate. Dev Psychobiol 2000;36(1):67-77.

216. DiPietro J A, Hilton SC, Hawkins M, et al. M aternal stress and affect influence fetal neurobehavioral development. D ev Psychol 2002;38(5):659-68.

217. Jugovic' D, Tumbri J, M edic' $M$, et al. N ew Doppler index for prediction of perinatal brain damage in growth-restricted and hypoxic fetuses. Ultrasound Obstet Gynecol 2007;30(3): 303-11.

218. Hundertmark S, Ragosch V, Zimmermann B, et al. Effect of dexamethasone, triiodothyronine and dimethyl-isopropylthyronine on lung maturation of the fetal rat lung. J Perinat M ed 1999;27(4):309-15.

219. Uno H, L ohmiller $L$, Thieme $C$, et al. B rain damage induced by prenatal exposure to dexamethasone in fetal rhesus macaques. I. Hippocampus. Brain Res Dev Brain Res 1990;53(2):157-67.

220. B arbazanges A, Piazza PV, Le Moal M, et al. M aternal glucocorticoid secretion mediates long-term effects of prenatal stress. J Neurosci 1996;16(12):3943-49.

221. Hayashi A, Nagaoka M, Y amada K, et al. M aternal stress induces synaptic loss and developmental disabilities of offspring. Int J Dev Neurosci 1998;16(3-4):209-16.
222. Rees S, Harding R. Brain development during fetal life: Influences of the intrauterine environment. Neurosci Lett 2004;361(1-3):111-14.

223. Sandman CA, W adhwa PD, Chicz-D emet A, et al. M aternal corticortropin-releasing hormone and habituation in human fetus. Dev Psychobiol 1999;34(3):163-73.

224. Glover V. M aternal stress or anxiety in pregnancy and emotional development of the child. Br J Psychiatry 1997;171:105-06.

225. Graham Y P, H eim C, Goodman SH, et al. The effects of neonatal stress on brain development: implications for psychopathology. Dev Psychopathol 1999;11(3):545-65.

226. W einstock M . D oes prenatal stress impair coping and regulation of hypothalamic-pituitary-adrenal axis. N eurosci Biobehav Rev 1997;21(1):1-10

227. W einstock M . A lterations induced by gestational stress in brain morphology and behavior of the off-spring. Prog Neurobiol 2001;65(5):427-51.

228. A miel-Tison C, Cabrol D, Denver $R$, et al. Fetal adaptation to stress: Part II. Evolutionary aspects; stress induced hippocampal damage; long-term effects on behavior; consequences on adult health. Early Human Dev 2004;78(2):81-94.

229. Buitelaar JK, Huizink A C, M ulder EJ, et al. Prenatal stress and cognitive development and temperament in infants. N eurobiol A ging 2003;24(Suppl 1):S53-60; discussion S67-68.

230. Davis EP, Glynn LM , Schetter CD, et al. Prenatal exposure to maternal depression and cortisol influences infant temperament. J A m A cad Child A dolesc Psychiatry 2007;46(6):737-46.

231. Gutteling BM, de W eerth $C, Z$ andbelt $N$, et al. Does maternal prenatal stress adversely affect the child's learning and memory at age six? J A bnorm Child Psychol 2006;34(6):789-98.

232. Benediktsson R, Lindsay RS, Noble J, et al. Glucocorticoid exposure in utero: $A$ new model of adult hypertension. Lancet 1993;341(8841):339-41.

233. Edward CR, B enediktsson R, L indsay RS, et al. Dysfunction of placental glucocorticoid barrier: L ink between fetal environment and adult hypertension? L ancet 1993;341(8841):355-57.

234. Hales CN, Barker DJ, Clark PM, et al. Fetal and infant growth and impaired glucose tolerance at age 64. BMJ. 1991; 303(6809):1019-22.

\section{ABOUT THE AUTHORS}

\section{Aida Salihagic Kadic}

Professor, Department of Physiology, Croatian Institute for B rain Research, M edical School, University of Zagreb, Zagreb, Croatia

\section{Maja Predojevic (Corresponding Author)}

Department of Obstetrics and Gynecology, U niversity H ospital 'Sveti Duh', M edical School, U niversity of Zagreb, Sveti Duh 64, 10000 Zagreb, Croatia, e-mail: predojevic.maja@gmail.com

\section{Asim Kurjak}

Professor, D epartment of Obstetrics and Gynecology; Dean, School of M edicine, Dubrovnik International U niversity, Croatia 